\title{
Shrinkage and thermal cracking in a reinforced concrete retaining wall
}

\author{
E. P. EVANS \& B. P. HUGHES
}

\section{Dr M. Moncrieff, Kier Ltd}

I wish to raise two points in connexion with the Paper which presents some much needed data obtained from field measurements.

62. The calculation in $\$ 46$ on the critical percentage of reinforcement must have been made by many engineers but the fact remains that adequate crack distribution can be achieved with lower percentages. The reason may be connected with the fact that plane sections normal to a bar do not remain plane immediately adjacent to it. The stress-raising effect of the bar may, therefore, propagate cracks at lower percentages. This is a problem that might usefully be examined using the dynamic relaxation technique described in Paper 7033.

63. Secondly, it seems likely that the recommended precautions will not prove to be very practical and the proposal to add ice to the water could be deleterious should some of the ice fail to melt prior to placing. Nevertheless the object of preventing a temperature rise by heat of hydration is a very desirable one.

64. The following contribute towards this:

(a) Avoiding excessively thick sections, in excess of 12 inches.

(b) In hot weather, stripping shutters as soon as possible.

65. In fact there appears to be a case for re-examining the $\mathrm{CP} 2007^{8}$ requirement for limiting the uncracked concrete stresses. This leads to thick sections with, in some cases, a relatively low percentage of reinforcement. There is a theoretical advantage in having thinner, more heavily reinforced sections.

Mr I. B. Aitken, Construction Manager, James Miller \& Partners Ltd

The Authors appear to have dismissed the shrinkage characteristics of concrete rather lightly-aggregate shrinkage is very much in vogue and blamed for a number of badly cracked structures. Knowledge, therefore, of the drying shrinkage values of the aggregates used would be of interest.

67. The subject in general raises the question of the designer in this connexion and his responsibility. Surely, for a good design of a concrete structure, the designer must accept the deficiencies of the material he will be using and design accordingly, viz. the designer should design the reinforcement to suit his, and only his, positioning of construction joints. He should also position narrow construction gaps (with reinforcement lapped therein) which, from his own constructional experience, he knows will suit the contractor's method of working. He should then virtually guarantee that what cracks there are will occur at the construction joints and that these, particularly in buildings, will not be detrimental both to appearance and efficiency.

68. My overseas experience with cracks, in walls 5-6 ft thick, up to $0.50 \mathrm{~mm}$ showed that cracking was eliminated when reinforcement was lapped in contraction gaps and that the temperature rise $\left(35^{\circ} \mathrm{C}\right)$ was exactly the same in summer and winter (cf. $\S 50$ ) but with a delay of 20 hours in the winter hydration temperature peak.

Paper published: Proc. Instn civ. Engrs, 1968, 39 (Jan.) 111-125. 


\section{DISCUSSION}

Other points of note were that the temperature gradient between concrete face and heart was $26^{\circ} \mathrm{C}$ at the hydration peak, and that cracking always occurred at seven days' age, viz. when the concrete was virtually back to ambient throughout.

69. I cannot agree entirely with the recommendation in $\S 50$. No contractor is going to pay for ice unless it is specified and the employer pays for the added complication for relatively small amounts of concrete in thin walls and slabs. A membrane curing compound would seem preferable to excessive surface cooling by water since the latter would only aggravate the temperature gradient across the section. Successive bay construction has its limitations; contraction gaps in certain thin section structures may be more advisable.

\section{Mr M. G. Handcock, Central Electricity Generating Board}

The Paper is a straightforward and interesting attempt to rationalize the effects of the heat of hydration and shrinkage on the cracking behaviour of a concrete wall. However, it has wider implications in the consideration of concrete structures generally where thermal and shrinkage stresses can be as high or higher than the load induced stresses. In addition to heat of hydration, thermal stresses can be produced by climatic and imposed operating conditions. The consideration of the properties of concrete and its behaviour under such conditions has entered into a number of Generating Board structures in recent years.

71. In a large number of instances temperature stresses, as considered in the Paper, induced by heat of hydration will be the largest stress ever experienced by the structure. From experience considerably higher temperatures can be found than the value of $5^{\circ} \mathrm{C}$ quoted in $\$ 13$ even for the centre of a 12 in. thick section. However, values will depend on a large number of factors, e.g. type of cement, fineness, cement content in the mix and temperature at time of placing and insulating value of shutters. A further point which should be mentioned is one of caution in using thermometers in pockets to measure temperatures. These can give erroneous readings if the

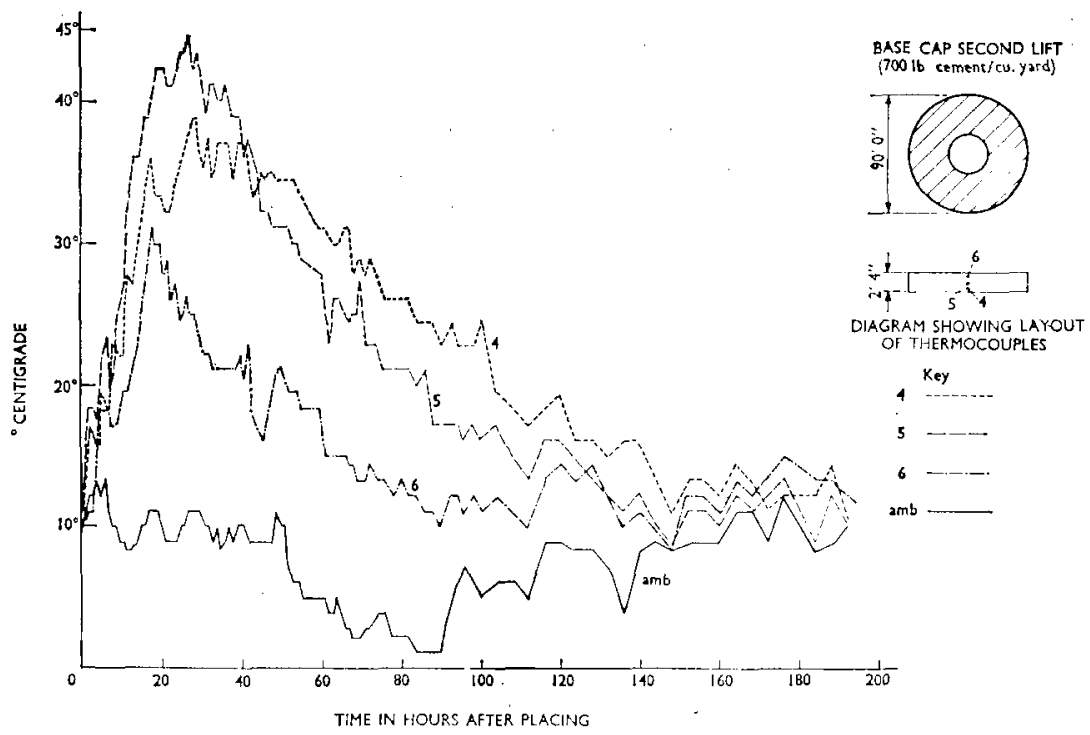

Fig. 10. Concrete pressure vessel 
pockets themselves disturb the heat pattern. Metal pockets for instance could form a heat sink with a conduction path through the metal wall to the outer face of the concrete, which in turn would modify the local temperature pattern within the concrete. Also loss of heat due to convection in the pockets can take place if they are left unsealed. A more satisfactory solution to the measurement of temperatures employed extensively by the CEGB is provided by thermocouples embedded in the concrete. From observations made using thermocouples typical temperature histories in a concrete pore are shown in Fig. 10.

72. With such temperature rises the thermal strains on cooling are such that cracking of the concrete would appear inevitable. Where a high strength concrete is employed with perhaps a $500 \mathrm{lb} / \mathrm{sq}$. in. tensile strength at seven days, the critical reinforcement from equation (6a) would be $1.25 \%$ - possibly an economically prohibitive amount in a thick walled structure.

73. In addition to the straightforward stresses considered in the Paper, differential thermal stresses will occur due to the temperature variation within the concrete section. Such thermal stresses can also be quite considerable and may be aggravated by too enthusiastic curing of exposed surfaces with cold water. The results could be the development of tensile shrinkage strains on final cooling inside a given block of concrete which could weaken the section without giving any indication on the surface.

74. Subsequent to curing thermal stresses are very often ignored in concrete structures but may well merit further attention. Concrete surfaces exposed to the sun must occasionally, even in the UK, reach very high temperatures causing a complete redistribution of stress in the section. (A concrete wall restrained from bending with a temperature differential across the thickness of $20^{\circ} \mathrm{C}$ could experience a compressive stress of $500 \mathrm{lb} / \mathrm{sq}$. in. on the hot face and $500 \mathrm{lb} / \mathrm{sq}$. in. tension on the cold face.) Under power station service conditions temperature differentials of the order of $40^{\circ} \mathrm{C}$ are quite possible in chimneys, nuclear pressure vessels, steampipe tunnels and turbine blocks, and so on, and careful consideration has to be made of the strains arising. Even on the domestic side, underfloor heating pipes and electrical floor heating in concrete structures must give rise to considerable stresses.

75. One mitigating factor in this problem is the creep characteristics of concrete. This is especially significant when considering heat of hydration since creep is very high at an early age and also increases generally with temperature. Even in later life creep can have a considerable effect. Results obtained ${ }^{8}$ show values of up to 1000 microstrains after 3 years' loading at $2000 \mathrm{lb} / \mathrm{sq}$. in. and $60^{\circ} \mathrm{C}$. Investigations into pre-stressed concrete pressure vessels show a complete redistribution of stress under such conditions with the possibility of some of the highest concrete stresses occurring after part of the imposed loadings has been removed.

76. Where the most onerous conditions are produced by the heat of hydration in a structure it may be that more attention should be given to reducing the actual rate of heat evolution by careful selection of cement and consideration of mix design $\mathrm{n}$ addition to the precautions given in $\S 50$. In this respect it would appear that the cement manufacturer is partly to blame for these troubles, since present-day Portland cement tends to be more finely ground than previously with a fineness in excess of that given by BS 12 for rapid hardening cement. "Such cement is probably more acceptable to the pre-cast industry where high early strength is required. The alternative for larger structures is a low heat cement but this would entail some cost penalty. One is tempted to speculate on the possibility of manufacturers grading their OPC by heat of hydration characteristics as is done in some continental countries. The contractor could then select a material more appropriate to the work.

\section{Mr K. R. Smyth-Osbourne, Sir William Halcrow \& Partners}

In general the practical relevance of the cracking of concrete walls is its effect on their water tightness. The Authors' measurements and Paper provide valuable information 
but not sufficient to design watertight walls, i.e. walls that crack at predetermined positions which can be sealed by previously embedded water bars.

78. The wall studied cracked at the construction joints and, apart from one crack, the cracks opened some weeks after casting. This is not typical especially for thicker walls which usually crack between construction joints and within a few days of casting. As mentioned by the Authors the main cause of this cracking is restrained thermal shrinkage. My observations suggest that in general it is the restraint offered to freshly placed concrete by the mature concrete on which it is placed which controls the pattern of cracking. Due to this restraint the fresh panel of concrete on cooling is stressed in the same way as if it was stretched along its base.

79. Cracking occurs when tensile stress overtakes tensile strength. At present detailed information is not available on the rate of development of the stress and strength in concrete walls and consequently these factors cannot be taken into account fully in their design. This is evidenced by the varied positions and occasions at which cracks occur in practice. In Fig. 2 two cracks are shown which are not referred to in the text. Could the Authors give some information on these, the crack at the base of lift 3 , panels 12,13 and 14, and the crack in lift 1 between points 3 and 4 ?

80. Measurements taken at two sites showed the temperature in concrete walls rising to a peak of $30^{\circ} \mathrm{C}$ above the placing temperature 24 hours after placing. This seems normal for thick walls with modern ordinary Portland cement. Even for a thin wall the rise of $5^{\circ} \mathrm{C}$ noted by the Authors seems low and suggests the peak temperature may have been missed. Adding ice to the mixing water is limited to cooling the water by about $10^{\circ} \mathrm{C}$ representing with a $0.5 \mathrm{~W} / \mathrm{C}$ a heat reduction of $5 \mathrm{cal} / \mathrm{gm}$ of cement. This may be significant on reducing a temperature rise of only $5^{\circ} \mathrm{C}$ but not where the rise is $30^{\circ} \mathrm{C}$ which would be associated with a heat of hydration of $70 \mathrm{cal} . / \mathrm{gm}$.

81. The figure of 100 microstrain for shrinkage indicated by the Authors is interesting. How much of this shrinkage occurred in the first few days after casting? In Fig. 6 the thermal blocks show greater shrinkage than the shrinkage blocks. How does this agree with the wall measurements?

82. I understand that the Cement and Concrete Association are investigating for the early stage the rate of evolution of the heat of hydration in concrete and the rate of development of strength in concrete. However, in order to estimate the development of tensile stress in restrained concrete, the actual unrestrained volume changes of the concrete need to be measured from the very first hours after placing. In addition, similar measurements should be made for paste and mortar. The problem of achieving no restraint to the concrete, paste or mortar might be solved perhaps by placing each in a plastic bag and floating it in liquid of equal density to the concrete, paste or mortar. Such measurements should provide quantitative information on the settling of concrete after placing, the effect of the restraints offered to the concrete by the shutters and ties, and the residual stresses and strains left in concrete after casting. This information seems relevant, not only to the production of more watertight, sound and durable concrete but also to low stressed structural concrete such as airfield and road slabs and dams.

\section{Mr J. D. Dewar, Readymix Services Ltd}

The Authors are to be commended for providing information on an aspect of reinforced concrete for which there are relatively few published data and, possibly as a consequence, which is often dealt with inadequately in design and construction.

84. Although the factor of safety against structural failure is almost invariably high enough to cater for any inadequacies, the factor of safety against severe cracking is often found to be little more, and sometimes less than, unity.

85. It may be desirable, as shown by the Authors, to specify higher percentages of reinforcement in parts of structures which require only nominal reinforcement for structural reasons, in order to provide a better safeguard against severe cracking. 
86. With regard to walls, CP 114 states that 'the minimum percentages of reinforcement $(0.20$ and $0.10 \%)$ specified may not always be sufficient to provide adequate resistance to the effects of shrinkage and temperature ...' It is not unknown for a contractor to provide additional reinforcement at his own expense rather than take the risk of severe cracking.

87. For walls, CP 2007 specifies a minimum of $0.3 \%$ reinforcement and states further that 'distribution reinforcement provided for the control of cracking ... shall be placed as near the surface of the concrete as possible. ...

88. I have examined recently, in different localities, two water retaining structures which had suffered severe vertical cracking of the walls. The walls in both structures were designed as cantilevers from the base slabs and were nominally reinforced, $0.3 \%$, in the horizontal direction with distribution steel placed inside the main vertical bars. In both instances the distribution steel was apparently insufficient, and too far from the concrete face, to resist initial contraction at the surface when the formwork was struck. Possibly due to base restraint some of these cracks developed eventually through the walls. It could be argued that more care could have been taken to protect the concrete immediately after striking but, on the larger of the two contracts, all obvious remedies in construction technique proved of no avail. For the smaller contract all the walls had been cast before the cracks were discovered.

89. I agree with the Authors' conclusion that much more emphasis should be placed on early curing to minimize effects due to thermal contraction. In this respect, I would suggest that differential contraction is a major factor promoting the initiation of cracks which may develop later into severe cracks. This is associated with both thermal shock and fast drying of the surface when formwork is struck too early, particularly in the winter, in hot dry weather and when rich mixes are employed.

90. With regard to less emphasis on curing to minimize drying shrinkage, the Authors do not state the type of aggregate used, but if it was of the low shrinkage type, e.g. quartzite, appropriate to parts of the Midlands, low drying shrinkage of the concrete would be expected. Many other aggregates, equally acceptable for concrete and in common use, would be expected to produce appreciably higher drying shrinkage.

91. The Authors refer to the low drying shrinkage of the test block. Was the humidity of the air recorded? In the winter months a higher average humidity might be expected and would result in a lower shrinkage of the concrete.

92. I would value the Authors' comments on what seems to me to be a major problem in the measurement of thermal and moisture movements, namely the establishment of a satisfactory origin. The reference points were fixed to the surface one or two days after casting the concrete following removal of the formwork, at which time, confirmed by the Authors' tests, the greatest rates of movement occur, particularly at the surface. The origin is thus always in doubt which makes absolute measurement impossible and comparison of movements difficult. It is sometimes possible for the greatest movements, including cracks, to have occurred before the reference points have been fixed and thus subsequent measurements and conclusions may have doubtful validity.

93. The reported information concerns concrete cast in the winter. Have the Authors additional information to support the extension of their conclusions to concrete cast in the summer? In particular, have they evidence to show that in this country the implementation of their recommended precautions $(a)$ and $(b)$, referring to the materials for concrete, would be economically justifiable and produce a substantial reduction in cracking problems?

94. With regard to construction methods, the Authors make only one recommendation, (c), which concerns the sequence of construction. I would suggest that the type of formwork, the size of bay, the time of striking and the delay between placing of adjacent bays may be as important as the sequence of construction.

95. With regard to the time of delay between placing adjacent bays, it may be of interest to note that for the $\mathbf{2 4}$ horizontal or vertical construction joints shown in 
Fig. 2, all four joints between bays cast with less than eight days' delay developed cracks and that all eight joints formed with a delay exceeding 36 days did not crack. There are numerous alternative construction sequences involving the same dates which could have increased appreciably the delay between casting of adjacent bays. Could the Authors suggest whether this would have improved or aggravated the extent of severe cracking?

\section{Mr E. B. Hilton, Assistant Engineer, Buckinghamshire Water Board}

The Authors make no reference to CP 2007 and in this connexion the problem of random cracking has been encountered in reinforced concrete reservoirs designed with propped cantilever retaining walls up to $18 \mathrm{ft}$ high, cast full height in continuous pours and in bay widths up to $16 \mathrm{ft} 6 \mathrm{in}$. Wall thicknesses generally similar to the wall under investigation by the Authors have been adopted, and a $1: 1 \cdot 6: 3 \cdot 2$ designed concrete mix.

97. Continuous horizontal distribution reinforcement of $0.3 \%$ is provided in accordance with the recommendation given in the Code and to date only mild steel round bars have been used for this purpose.

98. Vertical cracks have occurred in infill bays of alternate bay construction and also in bays cast consecutively, and have taken place in bays cast from 3 to 28 days after the last adjacent bay. The pattern of cracking is most commonly a single crack at about the mid point of the wall bay, extending from the thicker level for approximately $\frac{2}{3}$ of the wall height. This phenomenon has occurred during summer and winter construction but, in my opinion, will occur in weather conditions when large and rapid fluctuations in temperature are induced in the concrete. The cracks observed are of the order of $2 / 1000$ in. in width and, referring to equation (6a), this corresponds to a $u_{\mathrm{t}}$ value of $300 \mathrm{lb} / \mathrm{sq}$. in.

99. The minimum crack spacing given by the Authors' formula is apparently complied with in this application, assuming movement also takes place at the partial contraction joints provided in the design of the structure. The crack spacing formula would also suggest that relatively low steel ratios may be selected for predetermined cracking to occur at the construction/contraction joints in wall bays from 10 to $20 \mathrm{ft}$ long, although the effects of restraint at the wall footing may infiuence the formation of cracks, as considered in the Paper. Using high steel ratios, the inference is that a series of fine hair cracks at close centres may develop. In water retaining work it is easier to deal with one good crack than many small ones, if indeed this problem is going to occur, quite apart from the cost of introducing more steel to cope with an uncertain contingency.

100. Apart from the recommended precautions listed in the Paper, had the Authors given any consideration to the type of formwork used? It may be that the use of timber formwork creates a buildup of temperature and hence a high residual stress on cooling, whereas the use of steel shutters would enable more rapid dissipation of the heat evolved and a smaller temperature rise. It is interesting to note that cracking has not been evident in groundwork where members of similar thickness and proportions are cast, presumably due to rapid heat conduction and absorption by the ground.

\section{Mr J. Springfield, C. D. Carruthers \& Wallace, Consultants, Ltd}

All engineers attempting to record the action of full scale structures and to relate this action to known theory deserve our special encouragement. My only regret concerning the Paper is that the Authors were not able to carry their investigation further.

102. They have developed a theory for restrained reinforced concrete elements. It seems reasonable to assume that, after backfilling, the test wall would be restrained by the counterforts and the heavy base supporting a great weight of backfill. While the theory on which the value of $r_{\text {orit. }}$ is developed assumes full restraint, the equation 
for the crack spacing does not depend directly on this full restraint, but on the reinforcement stress being below yield. I realize that, by the theory, if $r<r_{\text {orit. }}$ the steel is assumed to have yielded. However, if there were to be some relaxation of the restraint, presumably $r_{\text {ortt. }}$ would be reduced, being closer to that for the test wall.

103. While it is common practice in Canada to provide expansion joints in cantilever retaining walls at about $40 \mathrm{ft}$ intervals, basement retaining walls are placed in lengths of 80-100 ft, in one lift of $14 \mathrm{ft}$ or more in height. In winter, when the fresh concrete temperature of $70^{\circ} \mathrm{F}$ may well be allowed to fall to an ambient temperature of $0^{\circ} \mathrm{F}$ or lower in a week or two, cracking does occur but it has not been regarded as a serious problem. I thought that the monolithic lengths involved were so great that base restraint precluded shortening of these walls. If this were the case, then it would not really matter how long a length of wall was placed in one operation, if it were over a certain critical length. This length may be estimated by equating the tensile capacity of the concrete to the frictional restraint of the supporting soil. The problem with this approach is that shrinkage begins immediately, prior to any tensile strength having been developed. Presumably, cracking occurs as soon as the concrete will no"longer deform plastically under shrinkage strain. Therefore, this approach would not yield valuable results or, put another way, it would predict infinitely short construction lengths at infinitely small concrete strengths; the wall would be fully restrained.

104. Equations (6) and (6b) for $r_{\text {ortt. }}$ are independent of this temporary condition, $r_{\text {orit. }}$ increasing as $\boldsymbol{u}_{\mathrm{t}}$ increases. The equation for the crack spacing is independent of this early condition if it is assumed, as the Authors have, that $u_{\mathrm{t}}$ is always equal to $\rho$. As it is thought that cracking begins at a very early age, a study of the conditions during this period seems to be essential to the development of reliable predictions.

105. Can the Authors suggest a theoretical basis for maximum length continuous concrete placement or do they think that such limits are so impractically small?

106. Because of the Authors' view that temperature variation is by far the greatest problem, the use of the term 'temperature reinforcement' in place of 'distribution reinforcement' seems appropriate. North American practice is to use more reinforcement in walls than the minimum quoted in the Paper; ACI-63 prescribes $0.25 \%$ and the National Building Code of Canada, $0 \cdot 30 \%$ if control joints are farther apart than $30 \mathrm{ft}$. This would be deformed reinforcement, which would have a marked effect on the crack spacing according to equation (8), but only if $r>r_{\text {orit. }}$.

\section{Mr J. Irving, Central Electricity Generating Board, Berkeley Nuclear Laboratories}

Berkeley Nuclear Laboratories are involved in theoretical work on concrete pressure vessels for the CEGB's nuclear power programme in which the problems of creep, shrinkage and thermal movement are of great importance. While I agree with the Authors that the main cause of cracking in lightly reinforced structures of narrow cross section is thermal stress induced by local restraints, I do not think that shrinkage can be ignored entirely.

108. In deriving their expression for $r_{\text {orit. }}$ the Authors have assumed that shrinkage is uniform across the section and that the strains measured in their control blocks were of a similar nature.

109. If shrinkage is directly dependent on moisture content and moisture loss occurs from the two large faces of the concrete exposed to the atmosphere then, for the sake of argument, a shrinkage strain distribution through the section of a parabolic form can be assumed similar to that shown in Fig. 11. In an unreinforced block the strain $\epsilon_{0}$ measured by demec gauges will be

$$
\epsilon_{0}=\frac{1}{3} \epsilon_{s \mathrm{~s}_{\max }} . . .4 . \quad . \quad . \quad .
$$

and the corresponding stress in the concrete will be

$$
f_{\mathrm{ot}}=E_{\mathrm{c}} \epsilon_{\mathrm{o}}\left(1-\frac{3 x^{2}}{d^{2}}\right) \quad . \quad . \quad . \quad . \quad . \quad . \quad .
$$




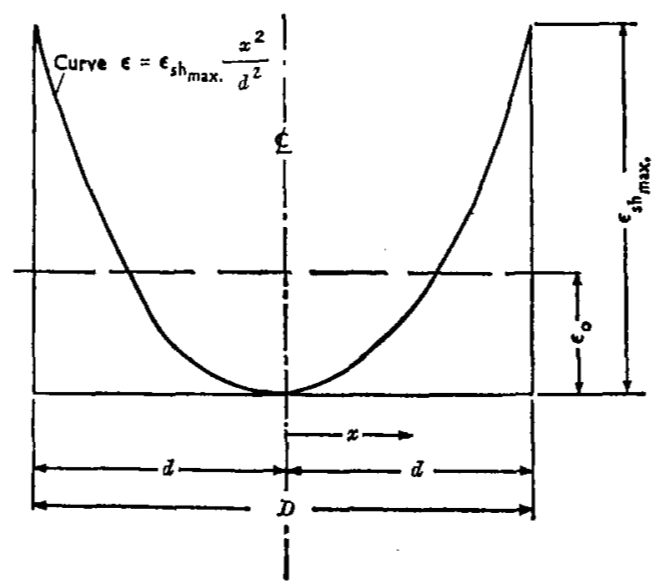

Fig. 11. Variation of shrinkage strain across section

110. It can be seen from equation (11) that if $E_{0}=2 \times 10^{8} \mathrm{lb} / \mathrm{sq}$. in. and $f_{\text {ct }}=330 \mathrm{lb} /$ sq. in. an observed strain of 82.5 microstrain can be associated with stresses approaching the tensile limit of the concrete.

111. The equivalent expressions to equation (11) for unrestrained and fully restrained reinforced sections are respectively

and

$$
\begin{aligned}
& f_{\mathrm{ct}}=E_{c} \epsilon_{0}\left\{\frac{1}{1+m r}-\frac{3 x^{2}}{d^{2}}\right\} \quad . \quad . \quad . \quad . \quad . \quad . \\
& f_{\mathrm{ot}}=3 E_{\mathrm{o}} \epsilon_{0} \frac{x^{2}}{d^{2}} \quad \cdot \quad \cdot \quad \cdot \quad \cdot \quad \cdot \quad \cdot \quad .
\end{aligned}
$$

112. Equation (12) shows that outer fibre stresses will be

$$
f_{x=d}=-2 E_{0} \epsilon_{0} \text { for small quantities of reinforcement }
$$

and

$$
\underset{x=d}{f_{\text {ct }}}=-3 E_{0} \epsilon_{0} \text { for extremely large quantities of reinforcement }
$$

For the restrained case, equation (13), reinforcement does not affect stresses in the concrete.

113. Thus, cracking can occur at quite low observed shrinkage strains and will be practically independent of the quantity of reinforcement.

114. The effect of the non-linear shrinkage distribution is to cause a tensile 'skin' to form on the surface of the concrete. This skin will search out weaknesses and cracking will first occur at these points to a depth consistent with the tensile strength of the concrete and the shrinkage strain distribution. In fully restrained members it would appear that when this type of 'partial penetration' cracking occurs limited bond slip may take place where the crack is of sufficient depth. Since the remaining concrete will be intact it seems likely that cracks of small width only will occur. In this case a modified form of equation (6a) can be used for determining $r_{\text {orit. }}$

$$
r_{\text {orit. }}=\frac{u_{\mathrm{t}}(1-k)}{3\left(f_{\mathrm{y}}+E_{\mathrm{o}} \epsilon_{0}\right)-m u_{\mathrm{t}}}
$$

where $x_{\mathrm{c}}$ at the limit of penetration of the crack is

$$
x_{0}=\sqrt{\frac{u_{\mathrm{t}}}{3 E_{0} \epsilon_{0}}} d=k d \text {. . . . . . . }
$$



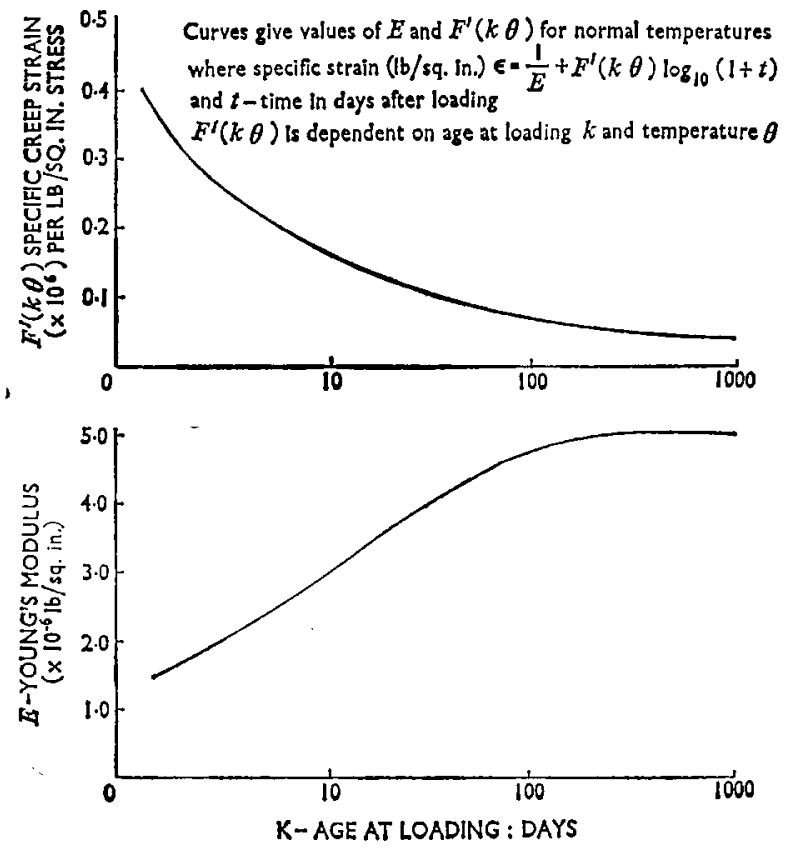

Fig. 12. Variation of Young's modulus and specific creep with age of concrete

115. Equation (14) gives a much lower value of $r_{\text {ortt. }}$ than the Authors' equation but will only apply to partial penetration cracks where limited bond slip occurs.

116. If, as assumed by the Authors, a full penetration crack occurs due to, say, cooling subsequent to casting, then bond slip must occur in order for the crack to open. The width of the crack and amount of steel needed for control would not appear to depend so much on the steel yielding due to contraction of the remaining intact length of the member as on the strength of bond between the steel and concrete.

117. Equation (6a), in which the substituted value of $f_{s o}$ is practically negligible compared to $f_{y}$, is merely a statement of equilibrium for simultaneous yield of steel and cracking of concrete for a member subjected to a load applied through the steel. As such it is extremely pessimistic. Although I do not have any experimental evidence, it seems likely that the actual steel stress after cracking occurs will depend upon the length over which bond slip occurs, and is therefore a function of steel surface area, and the bond properties of the concrete. This would apply only to lightly loaded structures since it is conceivable that if the structure is heavily loaded then yield could occur.

118. Although I sympathize with the Authors' attempt to suggest a simple method of calculating steel quantities, I think that use of equation (6a) would result in high percentages of steel being used to no effect. Have the Authors done any experimental work to substantiate their theory since writing the Paper?

119. If it is assumed that yield of the steel is not the major cause of randomly distributed wide cracks, then equation (8) gives a good guide to quantity of reinforcement since it is based on bond conditions. Equation (8) can be rewritten as

$$
\frac{\mu_{\mathrm{t}} D}{\rho 2 s} \geqslant r \geqslant \frac{\mu_{\mathrm{t}} D}{\rho 4 s}
$$



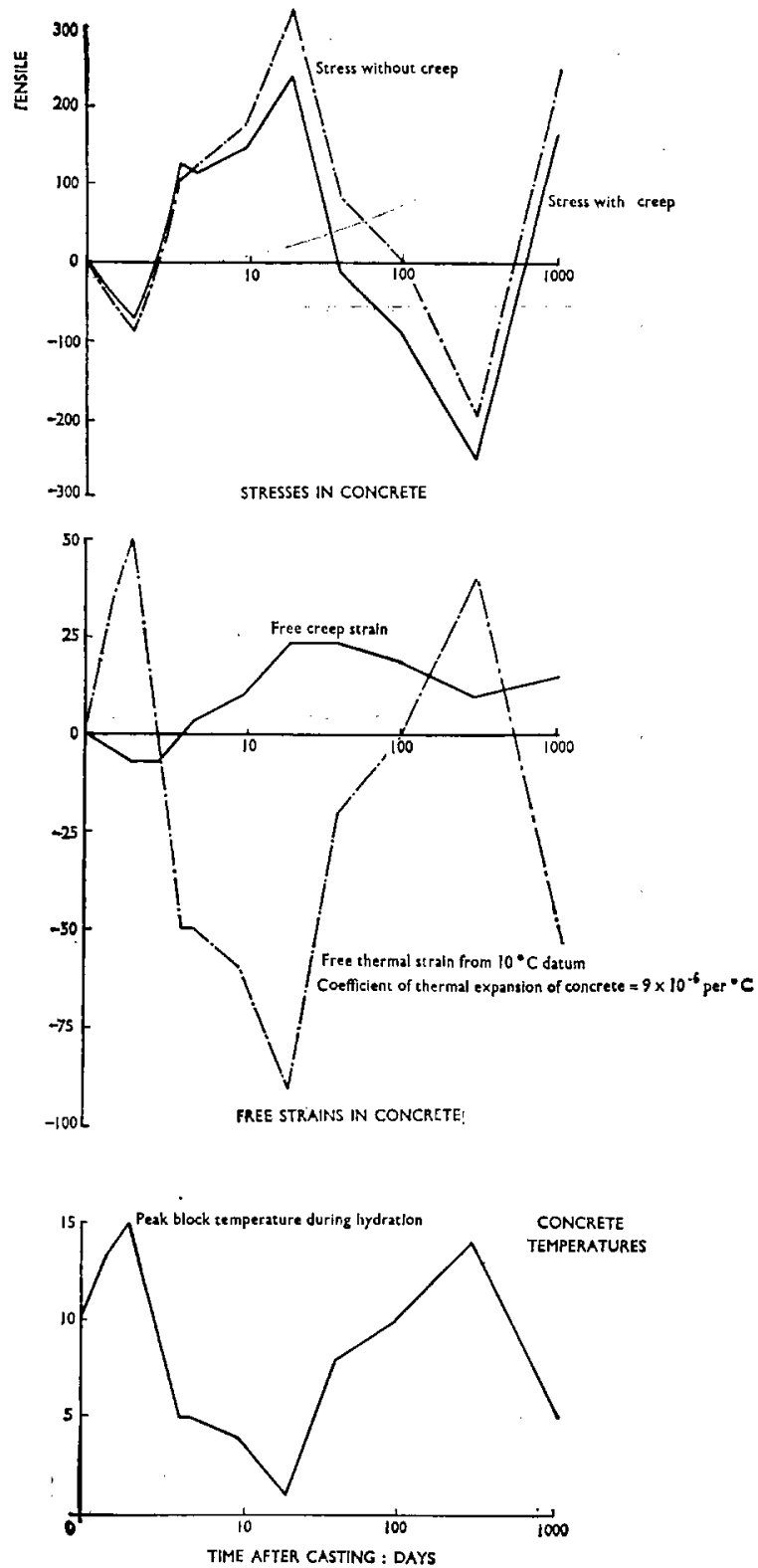

Fig. 13. Stresses and strains in a fully restrained concrete beam subjected to the temperature recorded by the Authors 

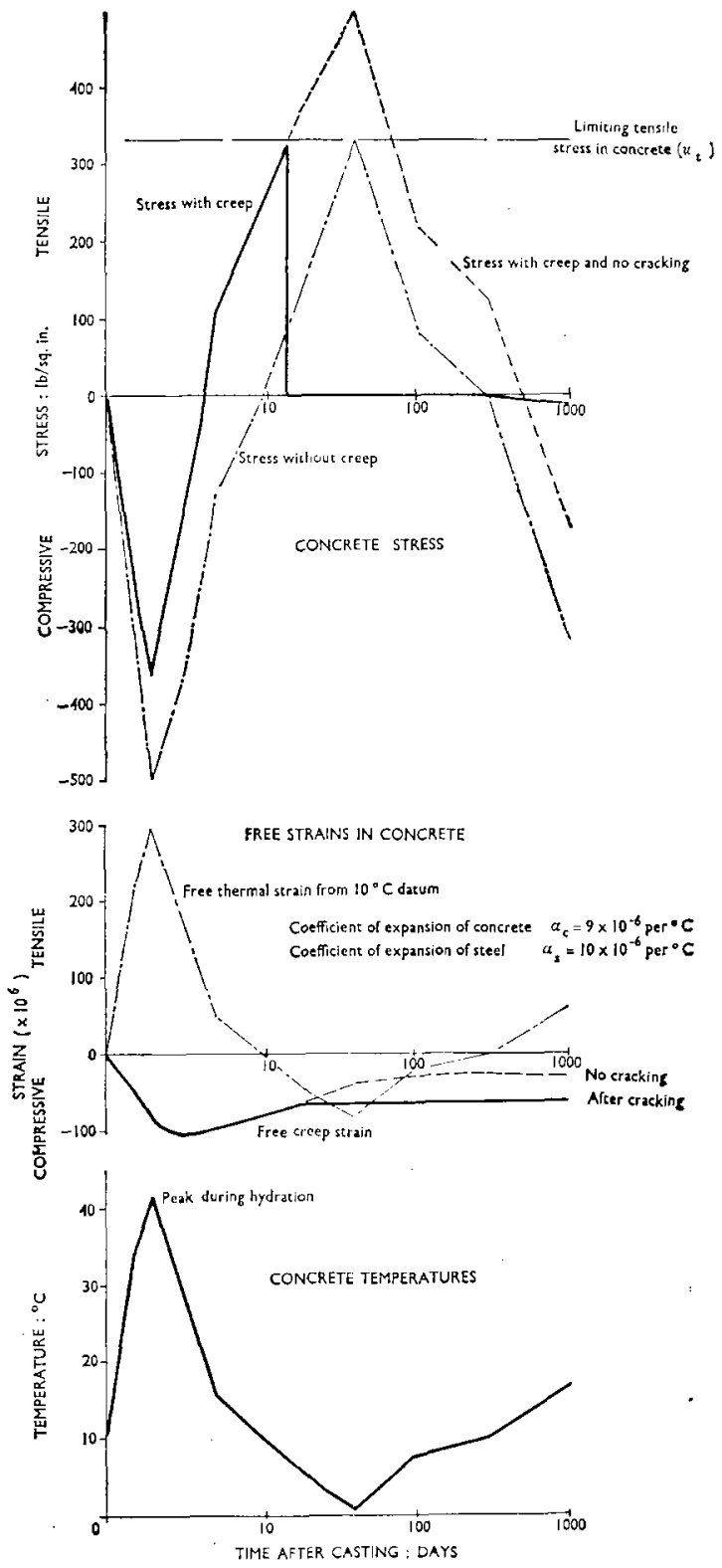

Fig. 14. Stresses and strains in a fully restrained concrete beam subjected to a varying temperature régime. Hydration temperatures assumed 
120. If $s$ is made equal to the length between probable weaknesses such as construction joints, then, for $\frac{1}{2}$ in. dia. bars

$$
\frac{1}{4 \times 156 \cdot 5} \geqslant r \geqslant \frac{1}{8 \times 156 \cdot 5}
$$

i.e.

$$
0 \cdot 16 \geqslant r \geqslant 0.08
$$

121. In structures where some restraint is present, whether it is shrinkage or thermal effects which cause the first full penetration cracks to occur will depend on the relative rates of drying and cooling. However, where the first full penetration cracks are those due to thermal stress and these cracks are sufficient to relieve fully the restraints in the structure, then subsequent intermediate cracking can still occur and is most likely to be due to non-uniform shrinkage of unrestrained sections. Since this type of partial penetration cracking is almost independent of steel ratio the intermediate cracks will be random in nature and will occur at local weaknesses in the surface of the concrete.

122. The Authors mention the effect of creep strain on fully restrained members. I have done some calculations assuming full restraint of a concrete section with a temperature history similar to that observed by the Authors. The variations of Young's modulus and specific creep with time used in the calculations are shown in Fig. 12 and are those reported by Browne ${ }^{7}$ for young concrete.

123. The method used to calculate stresses was an iterative time step method similar to that of Lewis et al. ${ }^{\theta}$ and a 'rate of creep' law was assumed to apply.

124. Figure 13 shows the results of the calculations for the temperatures recorded by the Authors. It can be seen that after reaching the peak hydration temperature, tensile creep relieves the peak tensile stress occurring on subsequent cooling. This is contrary to the Authors' assumption that considerable creep occurs due to compressive thermal stresses caused by the heat of hydration. It seems likely that the temperatures measured in the test blocks are lower than the true hydration temperatures. Browne ${ }^{7}$ quotes temperatures in excess of $45^{\circ} \mathrm{C}$ occurring at less than five days after casting. I therefore repeated the creep calculation with temperatures in the first 20 days made similar to those reported by Browne. The results of this calculation are shown in Fig. 14. If Fig. 14 is compared with Fig. 13 it can be seen that the higher temperatures and compressive stresses during hydration cause compressive creep of a larger magnitude than can be relieved during the rapid cooling process and instead of the tensile stress at the lowest temperature reached being relieved it is in fact increased by residual creep strain.

125. Of course, the Young's modulus and creep data used are open to doubt but the trend is shown by these results.

126. It is apparent from Figs 13 and 14 that tensile stresses on cooling can be reduced by two methods:

(a) Reducing the heat of hydration.

(b) Reducing the rate of cooling subsequent to casting.

127. In connexion with $(a)$ it would be interesting to know whether, in sections of 1-2 $\mathrm{ft}$ wide, the peak temperatures occurring within the concrete due to hydration are much affected by the air temperature. If they are not then a study of Figs 13 and 14 will show that it is better to cast in warm summer weather or keep the air temperature close to the temperature of hydration. Then, although compressive creep will occur due to the initial difference in temperature of the concrete and surroundings, subsequent tensile creep will be able to relieve tensile stresses during the slow cooling in the following autumn and winter.

128. The appearance of cracks in the retaining wall a few days after casting would appear to indicate that the low air temperature has caused cooling at a rate greater than that which would allow tensile creep to relieve thermal stress. 
129. In conclusion, while I agree with the Authors that thermal effects are probably the most important cause of cracking, I cannot concur with all their conclusions and recommendations. The steel ratios, as calculated from the equation (6a) appear to me to be over conservative. Cracking could be reduced by casting in warm conditions thus allowing a longer seasonal cooling period for tensile creep to occur. In this connexion, have the Authors observed other structures or carried out experiments to establish whether casting in the summer produces more or less cracking than winter casting?

130. Finally, could bays be cast overlapping the previous lift like brickwork? This would appear to be a good method of reducing crack width at construction joints since each successive lift on contraction will effectively prestress the one underneath.

\section{Mr G. Barrett}

This Paper calls to mind an extensive investigation into the causes of cracking of a concrete wall, carried out over a period of nine months from November 1955 to July 1956, in which I took part. The wall was part of a very large tank built above ground at Feltham, Middlesex. It was constructed in bays of $57 \mathrm{ft}$ with a $3 \mathbf{f t}$ gap (later filled in under specified weather conditions).

132. The wall was of counterfort design with five counterforts per bay, one at either end and three intermediates, thus providing four panels of plain walling each $13 \mathrm{ft}$ long. The wall was $18 \mathrm{in}$. thick and $24 \mathrm{ft}$ high. It was constructed in three lifts of $8 \mathrm{ft}$. The bottom lift was cast on to a substantial upstand, part of the floor, concreted some days previously. The shuttering consisted of a full height shutter on the inner face and three ranges of shutter, erected one on top of the other, to accommodate the counterforts. Thus the concrete could not be exposed until the whole bay had been completed, usually a period of about a week. The concrete was similar in constitution to that quoted in the Paper except that the slump never exceeded $\frac{3}{3}$ in. It was produced under laboratory conditions. The water contents of the aggregates were constantly reviewed and compaction factor tests were made for every separate mix. Every effort was made to ensure that the concrete was of uniform quality. The $2 \mathrm{cu}$. yd mixer was stop-watched to a minimum mix time of $3 \mathrm{~min}$. The shutters were filled in $2 \mathrm{ft}$ layers and compaction was obtained with six pneumatically operated $4 \mathrm{in}$. dia. heavy duty poker vibrators, operated to a pattern by stop watch and kept well behind the point of placing to obviate the danger of 'running' the concrete before the vibrators. On completion of a lift the top surface of the concrete was cleaned of laitence and washed to expose the aggregate and dried off ready for the new concrete of the next lift. No precautions other than to see that the surface was clean and dry were taken when the new concrete was poured. All horizontal joints were watertight when the tank came to be filled.

133. On stripping the first three bays consternation was caused by the discovery of serious cracks in the panels of the wall and various means such as altering the mix, adding extra distribution steel and early stripping of the shutters were tried without avail. It was then decided to investigate the thermal behaviour of the setting concrete.

134. For this purpose $3 \mathrm{ft}$ long pockets of electric conduits were inserted through the stop-end shutters and plugged at one end. Into these pockets mercury thermometers were placed and read at intervals during the setting period. The positions of these pockets were (a) 6 in. below the top of the upstand surface, (b) 6 in. above the bottom of the lift, $(c)$ in the middle of the lift, and $(d) 6 \mathrm{in}$. below the top of the lift. This process was repeated for each lift. As well as these temperatures, the temperatures of the cement and the mixing water were taken for each separate pour and, of course, a record of the ambient temperature was kept. In addition the temperature of the concrete as delivered to the shutter was taken.

135. The general distribution of the cracks, which were always vertical, was in the middle third of the panels. They began about $1-1 \frac{1}{2} \mathrm{ft}$ above the bed joint and 
tended to peter out about the same distance from the top of the lift. They were much more in evidence in the bottom lift than in the second lift and I do not remember finding an involuntary crack in the top lift. We therefore looked for the factors peculiar to this lift.

136. The pattern of behaviour of the concrete was as expected: a gradual and regular rise in temperature to a maximum while, of course, the concrete passed from a state of plasticity to one of complete rigidity. What had not been known was the extent of these movements.

137. The rate of rise was of the order of $14^{\circ} \mathrm{F} / \mathrm{h}$ for 24 hours after placing. This was quite characteristic over the whole series of observations. The temperature of the mixing water varied from $38^{\circ} \mathrm{F}$ in January to $60^{\circ} \mathrm{F}$ in July. The temperature of the cement, which was delivered in bulk to a hundred ton silo, averaged $73^{\circ} \mathrm{F}$, varying from $47^{\circ} \mathrm{F}$ to $90^{\circ} \mathrm{F}$. Ambient temperatures varied from $32^{\circ} \mathrm{F}$ in January to $75^{\circ} \mathrm{F}$ in July and while the effect of these differences may have been to raise the temperature of the concrete as placed, cumulatively they had no appreciable effect either on the rate of rise or the period to reach maximum temperature. It will be appreciated that the upstand temperature affected the temperature of the concrete at the area of contact by reducing it to some $10-15^{\circ} \mathrm{F}$ below that in the middle of the panel. The concrete in proximity to the cold upstand joint during the period of heating up and setting must develop compressive stresses which are relieved when the concrete temperature falls but the concrete in the middle of the panel, being unrestrained, expands during and after setting and develops tensional stresses as the temperature falls and, as a result, cracks. This was our conclusion.

138. Seeing no means of controlling these factors we decided to weaken the wall in the middle of the panels by the placing of 8 in. dia. 'ductubes' and filling the resultant cavities with clean, coarse aggregate and subsequently pressure grouting with a colloidal grout.

139. This procedure was followed with complete success. The walls duly cracked along the line of the ductubes and nowhere else, and the remedial measures were successful.

140. Some confirmation of the accuracy of the conclusions we reached as to the cause of cracking came when the $3 \mathrm{ft}$ gaps between the bays were filled. This operation was carried out in one pour from bottom to top. Here we had two vertical cold surfaces with a mass of fresh concrete between and, when we came to strip the shutters, we found small horizontal cracks had occurred six or seven feet apart in the middle of the new concrete.

141. From my experience during this investigation I do not think adding ice to the mixing water would have had any beneficial effect and, indeed, the suggestion is somewhat impractical when dealing with large outputs of concrete. In my opinion the most useful line of investigation into the inherent tendency of concrete to heat up during the critical period when the material changes from plasticity to rigidity would be to examine the chemistry of hydration of the cement to discover whether this could be altered to eliminate the production of heat.

\section{Mr A. W. Beeby and Mr J. Weaver, Cement and Concrete Association}

The Authors' Paper has been studied with considerable interest and it is felt that tests made recently by the Cement and Concrete Association may amplify the data in the Paper.

143. An attempt was made to simulate the conditions in an infill bay between two previously cast bays. Fig. 15 gives details of the test. The two end blocks were cast with the reinforcement anchored into them. The blocks were then bolted to the floor to give maximum restraint.

144. Hot concrete at a temperature of approximately $50^{\circ} \mathrm{C}$ was used for the infill bay and two unreinforced control blocks of identical cross section to the test bay. 

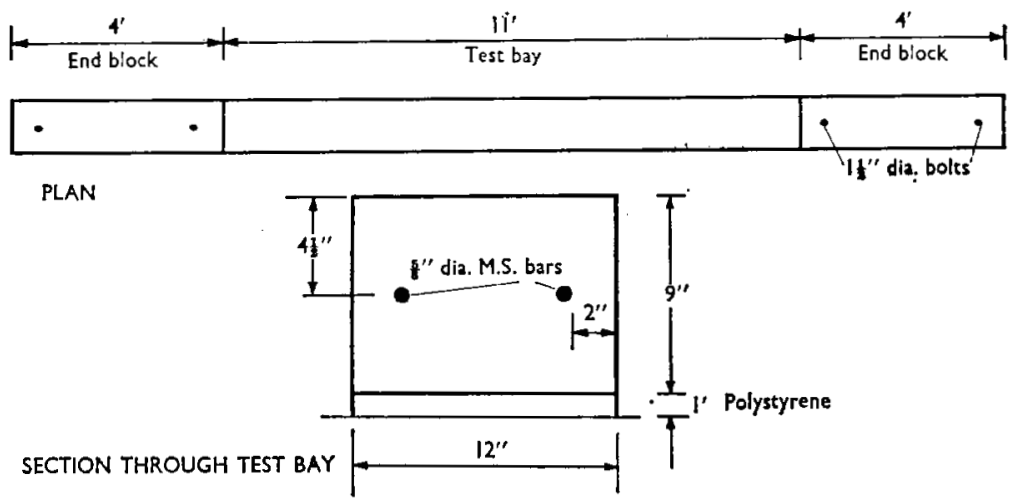

Fig. 15. Details of test

145. The temperature of the concrete in the test bay and control blocks and the air temperature were measured by 24 thermocouples. A continuous record of these temperatures was obtained from two 12 channel chart recorders.

146. The average concrete temperature in the test bay had risen to its maximum value of $61^{\circ} \mathrm{C}$, eight hours after casting. At this time studs were fixed to the concrete to allow measurement of surface strains using an $8 \mathrm{in}$. demec mechanical strain gauge. By 20 hours after casting, 0.007 in. wide cracks had formed at the construction joints. Temperatures, crack widths and surface strains were then measured at regular intervals until 20 days from casting when the test was discontinued.

147. The results obtained during the test are summarized in Figs 16, 17 and 18 . From the form of the curves it must be clear that almost all the movements can be attributable to thermal effects. This agrees with the Authors but it should be noted that little shrinkage would be expected to have occurred by this age. By the end of the test, the crack widths at the joints had reached 0.020 in. and no further cracks had formed.

148. It can be seen from Fig. 17 that the strains in the unreinforced control block are not very much higher than those in the test bay. This indicates a low stress in the concrete, estimated at not more than $120 \mathrm{lb} / \mathrm{sq}$. in. at the end of the test. The tensile strength of the concrete at this time, assuming it to be one tenth of the cube strength, was $490 \mathrm{lb} / \mathrm{sq}$. in. so it can be seen that there was no likelihood of further cracks forming.

149. While no measurements of steel stress or strain were made during the test, the stress state at the end of the test could be found. The reasoning involved in this is given in some detail.

150. At the end of the test, the unit was cut and one end removed. This released the stress in the steel at the remaining crack which closed to a width of less than 0.005 in. A force was then applied to the free end to return the crack to its initial value of $0.020 \mathrm{in}$. From this force, the steel stress at the crack was calculated to be $22000 \mathrm{lb} / \mathrm{sq}$. in., equivalent to a steel strain at this point of $73 \times 10^{-5}$.

151. To develop a crack width of 0.02 in. with this steel strain indicates that, effectively, the steel must be unbonded for a length of about 27 in. from the crack.

152. During casting, hot concrete was poured on bars at ambient temperature. Since these bars were restrained at their ends, the thermal expansion could be accommodated only by buckling. When the concrete set, the bars would be held in this buckled position and would thus be restrained from returning to their natural position 


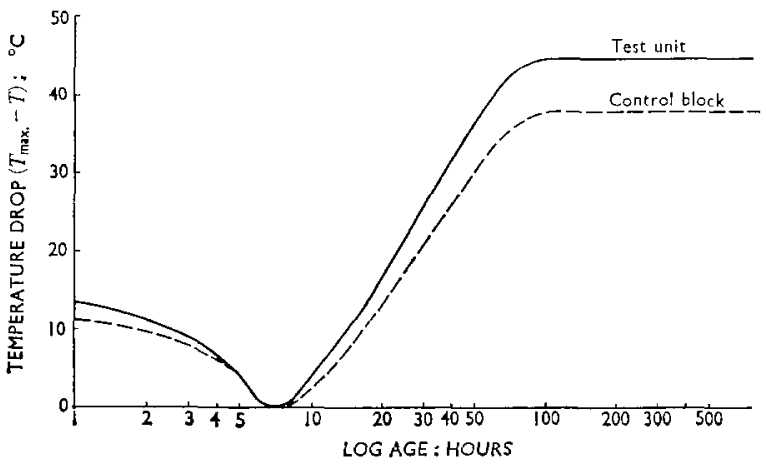

Fig. 16. Graph of temperature drop against time

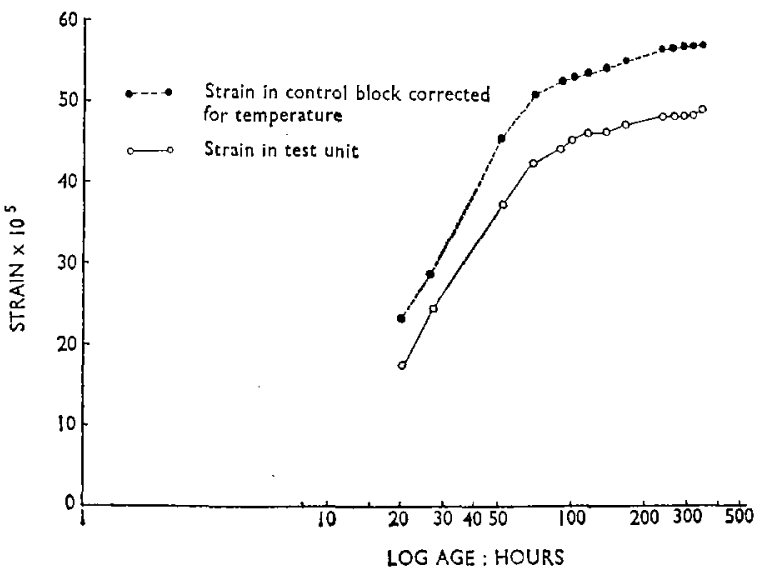

Fig. 17. Measured surface strains in test unit and control blocks

as the temperature fell. This would set up a uniform tensile stress in the bars. Assuming that the concrete is sufficiently stiff to restrain further buckling once vibration has ceased, and that the coefficient of thermal expansion of the steel is $1.1 \times 10^{-5} \mathrm{in} . / \mathrm{in} . /^{\circ} \mathrm{C}$ this stress can be calculated as $10400 \mathrm{lb} / \mathrm{sq}$. in.-equivalent to a strain of $34.5 \times 10^{-5}$.

153. By the end of the test, the end blocks were found to have moved inwards by $0.0149 \mathrm{in}$. This is equivalent to an averaged reduction in strain of $10.5 \times 10^{-5}$. Thus the average steel strain must be $(34.5-10.5) \times 10^{-5}=24 \times 10^{-5}$ equivalent to a tensile stress of $7200 \mathrm{lb} / \mathrm{sq}$. in.

154. Assuming bond to be effective at the centre of the test bay, the measured strain in the concrete must correspond to the amount by which the steel is compressed at this section. This strain was $49 \times 10^{-5}$. Since the steel starts with a tensile strain of $24 \times 10^{-5}$ the resultant strain is $25 \times 10^{-5}$ equivalent to a compressive stress of $7500 \mathrm{lb} / \mathrm{sq}$. in. 


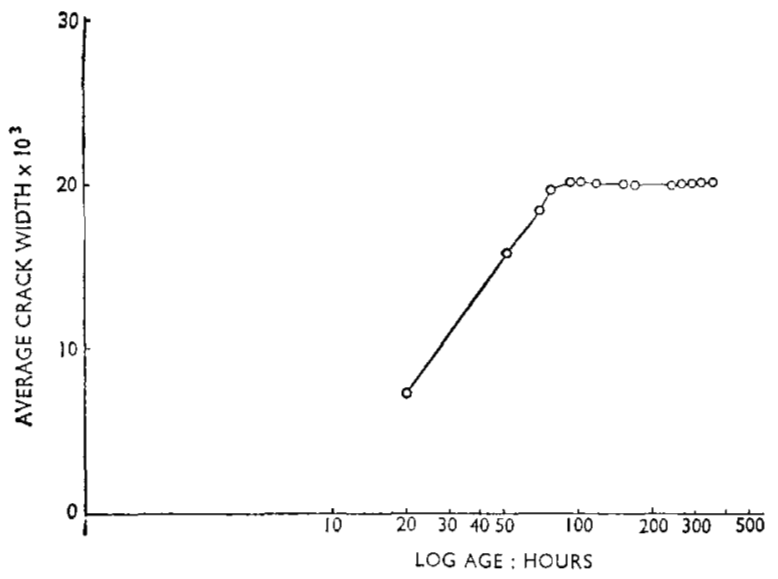

Fig. 18. Average crack widths at construction joints

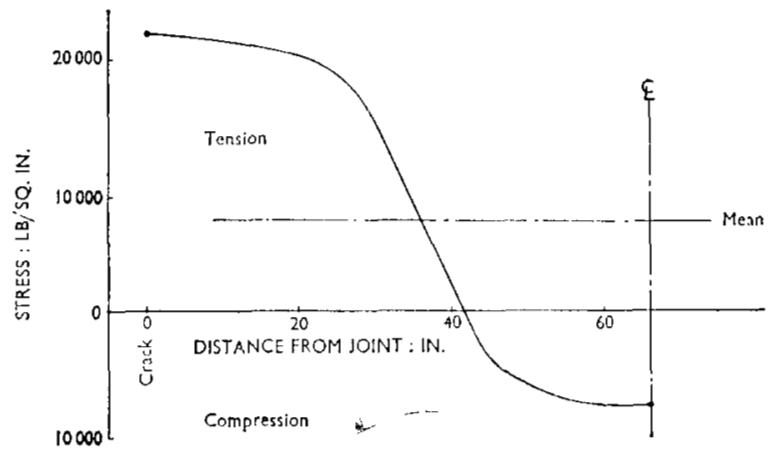

Fig. 19. Inferred variation of steel stress along test unit

155. Thus the end, central and average steel stresses are known; also, from the crack width, it is known that the steel is largely unbonded for a considerable length. From these facts it can be seen that the variation of steel stress along the test unit cannot be far removed from that shown in Fig. 19. Some general conclusions may now be drawn from these results.

156. The quantity $r_{\text {ortt. }}$ in the Authors' Paper, the steel ratio above which controlled cracking will occur and below which the steel will yield at the first crack, does not seem to be relevant in this instance. In the test described above, $r$ was below $r_{\text {crit. }}$ but it is clear that cracks formed only at the construction joints not because the bars had yielded but because of large scale bond failure.

157. It seems probable that what happens is that a considerable amount of movement occurs at an early age. This is sufficient to break down the bond between the steel and the concrete over a considerable length at a time when the bond strength is very low. As the concrete strength increases, so does the bond strength, thus 


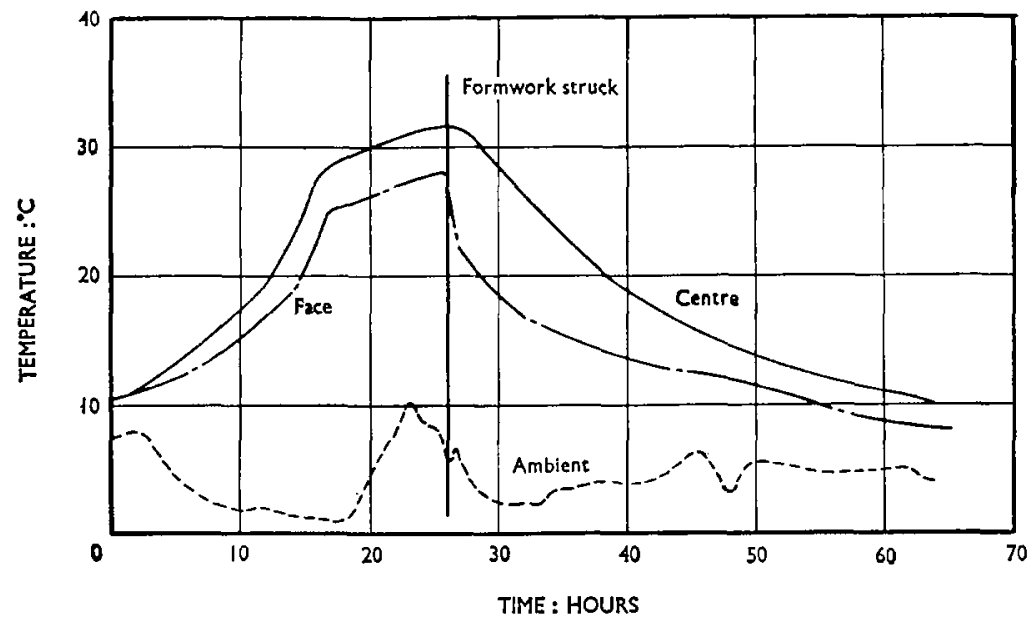

Fig 20. Concrete temperatures recorded by a $1 \mathrm{ft} 6$ in. thick wall placed in $\frac{3}{4}$ in. ply formwork

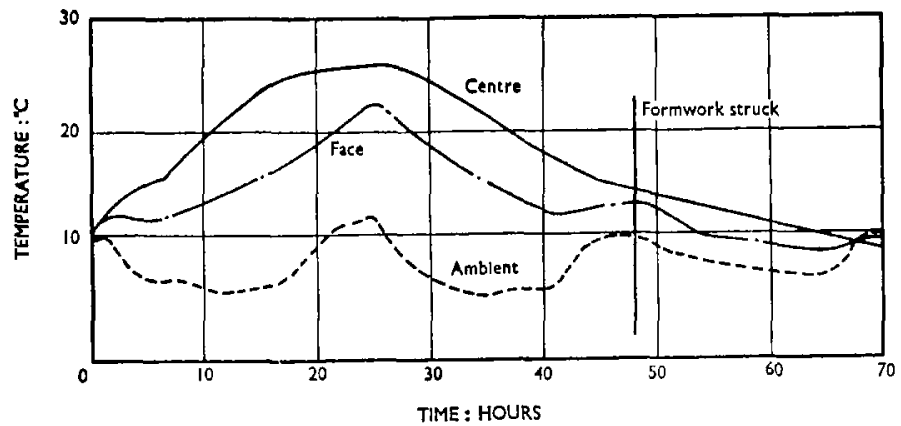

Fig. 21. Concrete temperatures recorded in a $1 \mathrm{ft} 6 \mathrm{in}$. thick wall in $\frac{1}{10}$ in. steel formwork

movements occurring later induce tensile stresses in the steel at the ends but these cannot become large because of the unbonded length available to absorb the movement.

158. Figures 20 and 21 show the early temperature histories at the centre of two concrete walls cast in $\frac{3}{4}$ in. plywood and $\frac{1}{16}$ in. steel formwork. The wall section was $6 \mathrm{ft} \times 6 \mathrm{ft} \times 1 \mathrm{ft} 6$ in. thick and the cement content was $580 \mathrm{lb} / \mathrm{cu}$. yd.

159. It can be seen that placing temperatures in both cases were similar while the ambient temperature during the first 24 hours was an average of $4^{\circ} \mathrm{C}$ lower in the test using timber formwork. The reduction in the rise of temperature effected by the use of steel formwork, for these particular conditions and disregarding the effect of the difference in ambient temperatures, was $6^{\circ} \mathrm{C}$ or about $25 \%$.

160. Hydrating cement evolves heat in an exothermic reaction. Therefore the placing temperature of the concrete will control the initial rate of heat generation; 
subsequent rates of heat evolution will depend upon the rate of heat dissipation from the concrete and formwork. Typical values for the conductance of $\frac{1}{10}$ in. thick steel formwork and $\frac{3}{4}$ in. plywood are 5600 and $1.3 \mathrm{BTU} / \mathrm{sq}$. $\mathrm{ft} h{ }^{\circ} \mathrm{F}$.

161. A reduction in the cement content to $460 \mathrm{lb} / \mathrm{cu}$. yd in a concrete wall formed in $\frac{3}{4}$ in. plywood under similar placing and ambient conditions caused a decrease in the temperature rise of about $25 \%$.

162. The effects of early age temperature change producing thermal strains and creep have not been defined clearly. In addition the effect of these factors in the relative stresses in the concrete and reinforcement has to be established; it is considered possible for conditions to occur when the reinforcement is in compression, caused by restraint to thermal expansion of the steel, while the concrete is virtually unstressed due to relief compressive stresses by creep.

163. The effect of aggregate type is significant in thermal movements in concrete. A comprehensive study was conducted by Bonnell and Harper ${ }^{8}$ who quote values for the coefficients of linear thermal expansion of wet concretes as follows:

$\begin{array}{lr}\text { gravel } & 12.3 \times 10^{-6} \text { per }{ }^{\circ} \mathrm{C} \\ \text { granite } & 8.6 \times 10^{-6} \text { per }{ }^{\circ} \mathrm{C} \\ \text { limestone } 6.1 \times 10^{-6} \text { per }{ }^{\circ} \mathrm{C}\end{array}$

164. Care should be taken to ensure that cooling of a warm structure should be slow to allow stress relief by creep. Fig. 20 shows the thermal effects of removal of an insulating form, causing loss of heat by radiation, convection and moisture evaporation. These conditions, although in this case not severe, cause thermal shock by cooling and shrinkage in the surface by moisture loss.

165. Water curing of warm concrete will reduce moisture loss from the concrete, but, if cold water is used, may cause thermal shock. Where necessary moisture loss should be prevented by the application of a suitable curing membrane.

\section{Mr A. A. Kaill}

One of the precautions which the Authors recommend is that fully effective water curing of the concrete should be undertaken until the end of the day after placing. I understand that it is envisaged that the shutters should be sprayed with water on the day of placing if necessary and the concrete itself sprayed the day after when the shutters have been stripped. Would the Authors advocate stripping the shuttering as early as possible to facilitate cooling the concrete?

167. In the case of bridge abutments, the concrete may be $3 \mathrm{ft}$ thick or more. By cooling the faces of the concrete the temperature gradient from the core to the face can be considerable and this may increase the risk of early cracking on the face. Have the Authors any experience of cracking attributable to this cause and do they consider rapid cooling accentuates this risk?

\section{Mr A. O. Erinoso. Taylor Woodrow Research Laboratories}

I welcome the Paper as a courageous attempt to rationalize the perennial problem of cracking in reinforced concrete walls.

169. During the past few years, we have been engaged in studying the movement and cracking tendencies of mass concrete monoliths, with particular reference to the biological shield of prestressed concrete pressure vessels. This work is still in progress and we believe that some of the data obtained from it could be applied usefully to smaller concrete structures like retaining walls.

170. I agree with the Authors that the usual empirical crack formulae derived for reinforced concrete beams cannot be applied satisfactorily to reinforced concrete walls, since, owing to the different support conditions when axially stressed, the deformation profiles of beams are vastly dissimilar to those of walls. Also, the stress distribution diagrams will be very different.

171. From the concrete mix proportions quoted by the Authors, I estimate that 
the cement content of the fresh concrete which was used in constructing the walls, will be about $550 \mathrm{lb} / \mathrm{cu}$. yd. Using typical ordinary Portland cement heat of hydration data, ${ }^{10.11}$ and heat flow methods of computation, ${ }^{12,13}$ an 18 in. thick gravel concrete wall (lift 2) containing $550 \mathrm{lb} / \mathrm{cu}$. yd of cement and insulated with, say, $\frac{3}{4}$ in. plywood shutters, I estimate that the maximum concrete temperature rise at usual site concrete placing temperatures will be about $12^{\circ} \mathrm{C}$. This maximum temperature rise will occur about 18 hours after mixing.

172. It seems therefore, that by taking the second set of temperature and strain readings about 28 hours after casting, and probably after the shutters were struck, the peak concrete temperatures and strains have been missed. Could the Authors explain why such a low concrete temperature rise was obtained for the shrinkage and thermal concrete blocks?

173. From $\$ 171$ and 172 , assuming a thermal coefficient of expansion of $12 \times 10^{-\mathrm{\theta}}$ in./in. ${ }^{\circ} \mathrm{C}$ for the gravel concrete, an underestimate of $7^{\circ} \mathrm{C}$ will give a concrete strain of $84 \times 10^{-6} \mathrm{in}$./in. that has not been accounted for. The cracking tendency of the wall will therefore be erroneously related to a lower thermal strain change than the strain change which actually occurred in the wall.

174. For example, even a 9 in. thick gravel concrete wall can undergo a temperature rise of $18^{\circ} \mathrm{C}$, when the concrete is placed at $12^{\circ} \mathrm{C}$. Further, Fig. 22 shows the concrete temperature and strain relationship with time after mixing, for a 9 in. thick $\times 11$ in. long $\times 8 \frac{1}{2}$ in. high gravel concrete block containing $710 \mathrm{lb} / \mathrm{cu}$. yd of ordinary Portland cement, and at a water/cement ratio of 0.46 . No additive was used. The concrete block was cast within $\frac{3}{4}$ in. plywood shutters. The top, bottom and two end faces of the block were insulated with 2 in. thick expanded polystyrene, in order to simulate wall continuity. Concrete temperature was measured by a copper/constantan thermocouple which was embedded at the centre of the specimen. Internal concrete strain was also measured by means of an embedded RRL/A vibrating wire strain gauge, coupled to a Maihak MDS/4 strain comparator. The concrete strain values have been corrected for change in length of the strain gauge wire due to change of concrete temperature, and for the acrylic gauge tube expansion, which occurred prior to the hardening of the concrete block. Readings of concrete temperature and strain were taken at 30 min. intervals.

175. By relating the concrete strains shown in Fig. 22 to the corresponding concrete temperatures, the thermal coefficient of expansion of the gravel concrete was

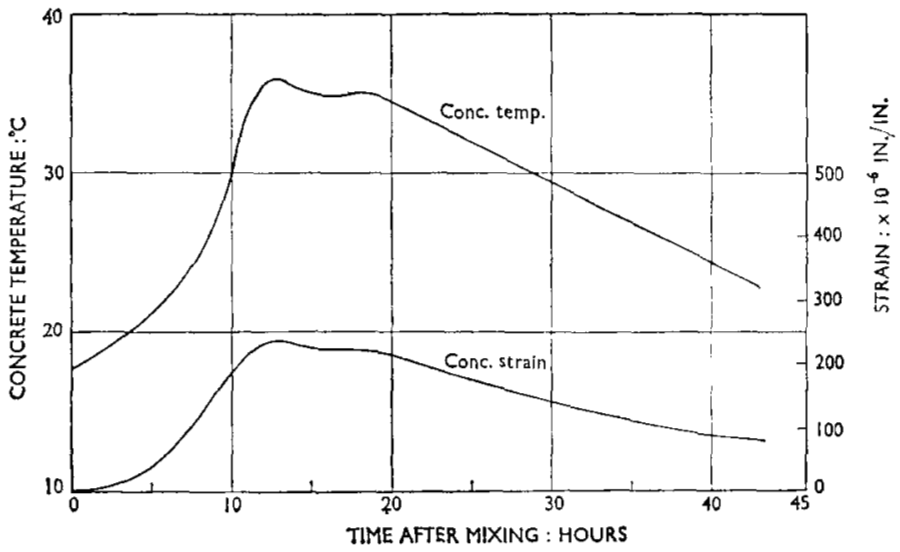

Fig. 22. Variation of concrete strain and temperature with time after casting 
determined as $12.0 \times 10^{-6}$ in./in. ${ }^{\circ} \mathrm{C}$; this is approximately the same as that of mild steel. This demonstrates the ineffectiveness of mild steel reinforcement, when used to accommodate thermal stresses in gravel concrete.

176. The Authors' conclusion that cracking was found to occur at almost all construction joints, is very important. It follows, therefore, that for the retaining wall which was described, had the construction joints been replaced by expansion joints, cracking would have been completely eliminated.

177. The derivation of equation (6) is interesting. My interpretation of the equation is that if it is accepted that cracks will form at construction joints (probably owing to poor bond strength or non-homogeneity of the concrete at that point), then the minimum steel ratio which will provide controlled cracking between successive construction joints is given by:

$$
r_{\mathrm{crtt}}=u_{\mathrm{t}} /\left(f_{\mathrm{yt}}+f_{\mathrm{so}}\right)
$$

This interpretation appears to be at variance with that of the Authors, in which if steel equal to $r_{\text {critt. }}$ were provided in a very long wall, controlled cracking should result. $f_{\text {ot }}$, which was replaced by $u_{\mathrm{t}}$ in equation (6), is most probably a function of the length of wall! Locations where $f_{\mathrm{ot}}$ equals $u_{\mathrm{t}}$ in the wall will therefore be dependent on the length of wall. Hence, the locations of cracks will also be a function of the wall length.

178. Figure 6 shows that even at about three months after casting, negligible concrete drying shrinkage has taken place in the 15 in. thick control specimens. This is surprising. Could the Authors indicate whether any tests were made to determine the effectiveness of the polythene seal against the migration of moisture from the thermal concrete blocks?

179. Figure 9 shows that during the first three days after casting, for the same temperature drop and drying shrinkage, the strain change for A3-6 was approximately twice that of D3-6, indicating the effect of foundation restraint on the 'young' concrete. It is surprising, however, that after three days, foundation restraint appears to have an insignificant effect on the strains at the top and bottom of the lift. Could the Authors supply a complete strain history similar to Fig. 9 for B3-6, C3-6 and E3-6? This will enable the degree of restraint to be determined for various points along the height of the wall, and also supplement future theoretical work on this subject. Further data on the strain readings at the end of the bay (i.e. A2-3, B2-3, C2-3, D2-3 and E2-3) will also enable more accurate estimates of crack movements to be made, especially in deciding the deformation properties of crack sealants, when these have to be used.

180. In order to have a general crack theory for reinforced concrete walls, it will be necessary to:

(a) determine the effect of foundation restraint on the wall,

(b) evaluate the concrete tensile stress and probable distribution, and

(c) compare the concrete tensile stress with the tensile strength at positions of predicted cracks.

\section{Mr Evans and Mr Hughes}

We wish to thank all those who have shown so much interest in the Paper and made valuable contributions to the discussion.

182. Dr Moncrieff comments that adequate crack distribution can be achieved with less reinforcement than the critical percentage. Distributed cracks can be achieved with low steel ratios if the local restraints are suitably distributed. $\$ 57$ states, '... It is the variable nature of these local restraints which can produce the wide variations in cracking behaviour which are frequently experienced.' If the local restraints are not favourable then $r_{\text {crit. }}$ is the minimum that is necessary to ensure distributed cracking. We agree, however, that $r_{\text {critt. }}$ may be reduced due to a stressraising effect of the bar itself, in certain circumstances, and could be taken into account 
if adequate data were available. An alternative approach which provides a modified value of $r_{\text {crit. }}$ is considered in the reply to Mr Erinoso.

183. Dr Moncrieff, Mr Aitken and Mr Barrett were not enthusiastic about adding ice to the mixing water in summer. The provision of an auxiliary water tank which retains unmelted ice and cools the water before it is gauged and mixed would not be very difficult, however. No ice would be incorporated in the concrete since the water pipe would exclude all ice particles of any appreciable size. Further comments concerning this recommendation are given later in the reply to $\mathrm{Mr}$ Smyth-Osbourne.

184. Mr Aitken states that ' . . . aggregate shrinkage is very much in vogue and blamed for a number of badly cracked structures.' This is the very point we emphasized when indicating that much of this blame is misplaced and should be directed towards thermal contraction. If the shrinkage characteristics of concrete appeared to be dismissed rather lightly it was because thermal effects for thin sections were now considered to be far more significant than had generally been thought previously.

185. Shrinkage clearly contributes towards cracking, as indicated in the Paper, but such troubles should be considered in terms of thermal effects first and shrinkage effects second. The incidence of badly cracked structures due to the use of aggregates with high shrinkage characteristics is probably not very high, since such aggregates are often suspect due to other undesirable characteristics such as high porosity. The irregular gravel aggregate used in the wall is commonly used in the area and provides concrete which has a low shrinkage.

186. We did not attempt to apportion responsibility for avoiding excessive cracking between designer and contractor. The object was to give guidance for both. However, since Mr Aitken presses the point, it would be reasonable for the designer to specify that the maximum temperature in the fresh $\mathrm{OPC}$ concrete as discharged into the formwork in the UK should not exceed $20^{\circ} \mathrm{C}$ in appropriate cases (or $10^{\circ} \mathrm{C}$ for RHPC concrete). The contractor could please himself how he achieved this. It is thought, however, that the suggestions given in $\$ 50$ are more effective and easier than, for example, utilizing evaporative cooling water or cooling water coils.

187. The maximum temperature to be specified for the fresh concrete for overseas contracts would clearly depend upon local conditions. A much higher maximum temperature would have to be tolerated in equatorial climates, for example, although this would be offset by the fact that the minimum temperatures achieved in winter would also be higher.

188. An excessive temperature gradient across the concrete section is undesirable, as pointed out by Mr Aitken. Equally, however, an excessive temperature gradient vertically is also undesirable. The latter requires that the generated heat is dissipated as quickly as possible so that the maximum temperature is reduced. The former requires, ideally, that the heat is dissipated from within the section and not only from the surfaces. This is not practical. It is practical, however, to minimize the vertical temperature gradient by surface cooling as advocated in $\$ 50$. It is true that this increases the temperature gradient across the section, but this increase is more tolerable than the vertical temperature gradient which induces cracks throughout the wall rather than surface cracks which will tend to close subsequently once the wall achieves normal thermal equilibrium with the surroundings. In any case, if the heat is not dissipated while it is being generated, the final temperature difference between the high maximum temperature which would be allowed to build up in the centre of the wall and the normal heat loss from the surface will be such as to induce a temperature gradient across the section which is still very significant.

189. Contraction gaps, because of their narrow width, always tend to introduce difficulties in cleaning out, poorly compacted concrete, and so on. Such difficulties could be tolerated if contraction gaps were otherwise preferable to continuous bay construction, but this is not so. If the same number of joints are used in continuous bay construction the length of each bay is little more than half the length of the main 
bays in alternate bay construction. Furthermore, stop ends have to be formed at both ends for alternate bay construction whereas a stop end need only be formed at one end for continuous bays. As pointed out in $\$ 50$ alternate bay construction does not justify, the extra difficulties which are entailed in normal construction. Indeed, it is difficult to envisage a situation where alternate bay construction would be justified.

190. Mr Handcock rightly points out that thermal and shrinkage stresses can be as high or higher than the load induced stresses for other concrete structures besides concrete walls. Regarding the temperature measurements the Authors agree that thermocouples would have been preferable to thermometers and these are in fact being used in present work. ${ }^{14}$ The thermometers used, however, did not have metal cases and the holes were lagged.

191. The critical steel ratio for equation (6a) is indeed high for high strength concrete. If this equation is applied to massive structures such as those mentioned by $\mathrm{Mr}$ Handcock it is suggested that $r_{\mathrm{crit}}$. be used for a $12 \mathrm{in}$. or $18 \mathrm{in}$. thickness adjacent to each exterior face. The Paper did not attempt to consider massive structures so that experience or further work would be necessary to determine what minimum thickness of surface concrete would require $r_{\text {crit. }}$ (or slightly more steel since the 'core' concrete would transmit additional stresses to the 'surface' steel).

192. Mr Handcock gives the right emphasis when he states that '. . differential ... thermal stresses ... may be aggravated by too enthusiastic curing of exposed surfaces with cold water'. The following should perhaps be added to $\S 50(b)$ 'Moderate cooling starting as soon as possible after placing should be attempted. Fully effective water curing of the concrete can be achieved by ensuring that the surface is maintained moist by a suitable covering of wet hessian.' Maintaining the hessian wet should involve brief spraying with water at regular intervals: not a continuous torrent of ice-cold water. Insulating shuttering should be stripped as soon as possible in warm weather.

193. We agree that thermal stresses other than those due to hydration are also very often ignored and may well merit further attention. We cannot agree, however, that creep is necessarily a mitigating factor '.. . when considering heat of hydration since creep is very high at an early age and also increases generally with temperature'. It is precisely because the initial compressive creep strain in the concrete is high following the rise in temperature due to the heat of hydration that cracking is liable to occur when the concrete cools down again. The subsequent tensile creep strain is inadequate to offset this initial compressive creep strain. It is agreed that creep is often a mitigating factor but not in this particular instance if the weather is warm.

194. We also agree that more attention should be given to reducing the actual rate of heat evolution by careful selection of cement and consideration of mix design. Trying to offset poor quality control by using 'an extra bag of cement' may be permissible for a minor contract but it is not satisfactory for reinforced concrete work in general. Mr Dewar also comments on the dangers of rich mixes. Mix design for high quality concrete which enables a minimum amount of cement to be used for any available aggregates has been described elsewhere. ${ }^{15}$ Rapid hardening Portland cement has possible disadvantages due to fineness with respect to both heat of hydration and workability which are often given too little consideration.

195. Mr Smyth-Osbourne comments that the cracking of the wall which was studied was not 'typical'. It is suggested that the reason for this is that the lifts were cast in winter or spring such that the ambient temperature was not unduly high. If long bays had been cast in summer then 'typical' cracking between construction joints and within a few days of casting could have been expected if none of the recommendations given in $\$ 50$ were followed. We agree that the restraint to the freshly placed concrete is generally provided by the mature concrete on which it is placed. The crack at the base of Lift 3 for the end bay is considered in the reply to Mr Dewar. The cracks between points 2 and 3 , and 3 and 4 were noticed after 40 and 75 days respectively. 
The gauge readings for $2 / 3$ were more typical in that they had remained approximately constant whereas $3 / 4$ had fallen as for typical readings for uncracked gauge lengths. No sudden increase in gauge length occurred when either of these cracks was noticed. The recommendations given in this Paper should not be read in isolation. The temperature rise in walls can, of course, rise to a peak of $30^{\circ} \mathrm{C}$ above the placing temperature if no precautions are taken. However, if steel shuttering is used, for example, then the maximum temperature rise is greatly reduced. Similarly, it is very common for the water tank for a mixer to be exposed directly to the sun's heat such that the temperature of the water after the lunch break can be very high. An awareness of the dangers involved, by taking elementary shielding precautions for all the materials involved can easily reduce the temperature of the mixed concrete by $10^{\circ} \mathrm{C}$. Under these conditions a further reduction in temperature by adding ice to the mixing water is not insignificant.

196. Mr Smyth-Osbourne and $\mathrm{Mr}$ Erinoso commented on the low temperature rise in the test blocks. The rise of $5^{\circ} \mathrm{C}$ we noted was perhaps a little low because of the method of measurement as noted in the reply to Mr Handcock. The shuttering was stripped very quickly and in cold weather, however, so that a very small rise was to be expected.

197. The fact that the strains for the shrinkage and thermal control blocks were similar, within experimental errors, indicated that drying shrinkage in the winter weather which then prevailed was negligible. The autogenous shrinkage in the first few days after casting would be very small (less than 20 microstrain). Mr SmythOsbourne's comments on estimating the development of tensile stress in restrained concrete are very interesting.

198. Mr Dewar makes several useful comments. We agree that both the type of aggregate and the weather conditions for the concrete cast in winter were particularly favourable for a very low drying shrinkage. While excessive thermal shock due to early striking of insulating formwork in winter should be avoided, early striking of the formwork in cold (but not freezing) weather can still be desirable. It is suggested that this can be achieved by easing the formwork away from the concrete slightly and then leaving for a few hours before complete removal. This would encourage a more gradual build-up in heat loss while still enabling heat losses to occur quickly. Fully effective water curing immediately after striking the formwork is vital, especially in hot dry weather.

199. We agree that a satisfactory origin for shrinkage and thermal strain readings is difficult to establish. However, fairly flexible vibrating-wire strain gauges are being cast into the concrete in present work ${ }^{14}$ so that it is hoped to record movements which occur as soon as the concrete is strong enough to actuate the gauge. This later work should also provide a comparison between concrete cast in summer and in winter. No actual cost data are available concerning the implementation of recommendations $(a)$ and $(b), \S 50$. Perhaps $(a)$ and $(b)$ should have been interchanged since it should only be necessary to add ice to the mixing water if $(b)$ alone is inadequate.

200. Mr Dewar rightly points out that construction methods other than (c) are important. Steel formwork, shorter bay lengths and early striking of the formwork all reduce cracking. With regard to the time of delay between placing adjacent bays it is felt that only the horizontal crack between lifts 2 and 3 could be attributed to too short a delay. Seven of the eight joints formed with a delay exceeding 36 days and which did not crack were horizontal. Such joints would not be expected to crack since there is, in general, no vertical restraint at all acting at the top of the lift. There is, instead, a favourable compression load due to self weight. Concentrated horizontal restraints could theoretically produce a shear crack along a horizontal joint: for example, Counterfort No. VIII could conceivably have produced a restraint at the end of Lift 3 (Fig. 2) which was more significant than the usual restraint exerted along the bottom of the freshly placed concrete (i.e. by Lift 2 in this case). It is felt, however, that this is highly unlikely for two reasons. First, the true shear strength 
of concrete is little less than the compressive strength. Second, the restraint which can be offered by the hardened concrete in the lift below is very significant and is not likely to be modified very appreciably by a counterfort which has been cast as part of the fresh lift and therefore contains concrete which is just as immature as the concrete in the rest of the lift. The most probable explanation is that it is a surface crack which could have been induced by thermal shock and then widened by bending stresses. The end bay of Lift 3 was cast only eleven days after Lift 2 and, in addition, the end bay of Lift 4 was cast after a further eight days only. The shuttering could have been lifted immediately from Lift 3 and placed in position for Lift 4. Any lateral impact at the top of Lift 3 would have had to be taken by the immature concrete without any assistance or support from concrete in bays on either side.

201. The delay between casting adjacent horizontal bays would again appear to depend upon heat dissipation, shrinkage and stresses induced in the immature concrete while erecting adjacent shuttering. Three to four days is more than adequate to dissipate the heat of hydration from a relatively thin wall. If effective water curing is maintained for $30 \mathrm{~h}$ after casting some drying shrinkage will occur after this period. Any difference in drying shrinkage after two days and after four days, for example, would be very small in most cases and would therefore be of less practical importance than the other two factors.

202. The stresses imposed on immature concrete due to the erection of shuttering for an adjacent bay horizontally are much less than for the adjacent bay vertically above. Suitable recommendations would therefore be as follows.

203. 'Immature concrete should not be overstressed due to temporary loading from the erection of shuttering. Shuttering horizontally adjacent to immature concrete in a wall shall not be attached until such concrete is at least three days old. Shuttering which is vertically above immature concrete in a wall shall not be attached until such concrete is at least 14 days old.'

204. 'Insulating shuttering should be eased away from the face of freshly placed concrete in walls immediately the concrete has achieved adequate strength.' This could frequently be as little as ten hours or less in warm weather. The shuttering should be left approximately in place with a small gap between itself and the concrete for a significant period (about six hours in warm weather) and then removed completely. Non-insulating formwork (i.e. steel shutters) is clearly preferable for concreting in warm weather and highly desirable for hot weather since a moderate heat loss occurs almost immediately after concreting and steadily builds up. In this case the cooling process can be accelerated by applying effective water curing as soon as the shutters can be struck since the possibility of thermal shock (i.e. sudden large increase in heat loss) is greatly reduced.

205. The aim of effective water curing should be to keep the covering of hessian or similar material consistently wet. This involves frequent spraying with moderate amounts of water to saturate the hessian. Hosing with water such that torrents of water flow down the face of the concrete should be avoided, especially at the beginning of effective water curing. Water cooling is too intermittent, sudden and intense. Water curing on the other hand prevents drying out and provides moderate, continuous and even cooling by evaporation.

206. Mr Hilton's contribution provides further useful observations which confirm many of the results and conclusions given in the Paper and earlier discussion: crack spacing, vertical cracks occurring irrespective of time delays in casting adjacent bays of from 3 to 28 days, wider cracks at the base rather than at the top of the lift, superiority of steel shutters for heat dissipation, and so on.

207. We did not ignore CP 2007 deliberately. Its recommendation of $0.3 \%$ horizontal distribution steel is closer to $r_{\text {critt }}$ than the lower value for structures which are not water-retaining. Mr Hilton comments that 'in water retaining work it is easier to deal with one good crack than many small ones, if indeed this problem is going to occur... Remedial measures are unnecessary if large cracks are 
predetermined and small cracks are made small enough. Three possibilities are as follows:

(i) The provision of relatively low steel ratios across construction/contraction joints with adequate provision for water retention in the form of water bars, etc., with a maximum bay width given by the minimum crack spacing predicted by equation (8). If the steel ratio across the joint is only one half that in the bay itself, for example, then the opening-up of the cracks at the construction joints can accommodate normal contractions due to shrinkage and thermal movement subject to the restraint along the base. A minimum steel ratio within the bay of $0.2 \%$ should ensure that intermediate cracks within the bay due to concentrated restraints at the base are avoided.

(ii) Provision of joints as for (i) but with a maximum bay width given by the maximum crack spacing (i.e. twice minimum) predicted by equation (8). The width of the intermediate crack which may occur is then given by putting $s=s_{\min }$. in equation (9), that is:

$$
\Delta=s_{\min .}\left(\epsilon_{\mathrm{sh}}+\epsilon_{\mathrm{th}}-\epsilon_{\mathrm{ult}} / 4\right) \quad . \quad \cdot \quad . \quad .
$$

This value must not exceed $0.1 \mathrm{~mm}$ for watertightness according to $\mathrm{CEB},{ }^{3}$ i.e. half the maximum width recommended for normal external exposure to the weather.

(iii) No special provision at joints and the use of a steel ratio which is equal to

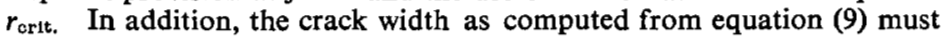
not exceed $0.1 \mathrm{~mm}$.

208. The relative economics and convenience of each alternative depends upon the particular application. The cost of providing the maximum number of predetermined joints, and any remedial work which is often associated with such joints, for (i) may or may not be offset by the saving in steel as compared with (iii). The design for the reinforced concrete reservoirs referred to by Mr Hilton appears to have chosen the middle course represented by alternative (ii). The width of the intermediate cracks is stated to be about $0.05 \mathrm{~mm}$ so that the reservoirs in Buckinghamshire more than comply with the CEB recommendations.

209. It follows, therefore, that ' $\ldots$ the inference . . . that a series of fine hair cracks at close centres may develop' has already been applied, in part, by Mr Hilton. However, if saving in steel is considered to be of paramount importance in a particular instance then a satisfactory design could be obtained using alternative (iii) if the arbitrary requirement of $0.3 \%$ minimum steel given in CP 2007 were ignored. It is not felt, however, that the provision of sufficient contraction joints in order to obtain the maximum saving in steel would always, or even generally, be justified.

210. We thank Mr Springfield for his encouragement and are pleased to mention that the work is continuing. Present work includes the determination of external and internal concrete strains, steel strains, internal surface temperatures, and moisture contents. ${ }^{14}$ Local restraints which are well distributed along the base of the lift can give an $r_{\min }$. value which is less than $r_{\text {orit }}$, as explained in $\$ \S 37-39$. However, partial restraint does not affect $r_{\text {crit. }}$ It does affect the width of the cracks and, indeed, whether or not the predicted cracks for full restraint ever in fact materialize. $\$ 47$ explained that intermediate cracking within construction bays was unlikely for the test wall since $r$ was less than $r_{\text {crit. }}$ This was confirmed by the results.

211. Mr Springfield queries the maximum continuous length for concrete placement with full restraint. Equations (6)-(9) were derived for this very case so that: it is difficult to understand why he thought that the limit might be '... impractically small'. Provided that $r \geqslant r_{\text {crit. }}$ and $\Delta \leqslant$ permissible crack width a continuous length is perfectly satisfactory. If shorter bay lengths are used then the crack width $\Delta$ actually observed can be reduced considerably by the reduced restraint 
at the free end. The Canadian Code value of $0.30 \%$ of deformed reinforcement quoted for bays exceeding $30 \mathrm{ft}$ is much nearer the $r_{\text {crit. }}$ value.

212. Mr Irving has made some interesting calculations for both shrinkage and creep effects. We agree that shrinkage should not be ignored entirely; $\$ 51$, for example, stated that "The primary cause of cracking .... is thermal movement, since this can greatly exceed the shrinkage movement.' $\$ 52$ then concluded that a change in emphasis was necessary, not that shrinkage should be ignored entirely.

213. Mr Irving points out that the shrinkage distribution across a section is non-linear such that a tensile 'skin' forms on the surface of the concrete. It is then suggested that 'partial penetration' cracking occurs for which a modified lower value of $r_{\text {orit. }}$ is determined. It is, however, necessary to note the following facts.

(i) Shrinkage will undoubtedly try to occur as shown in Fig. 11 but since it is very effectively restrained by the inner core the tensile stresses will be greatly reduced by creep.

(ii) 'Partial penetration' cracks will be distributed as a series of fine hair cracks (due to the uniformly distributed restraint offered by the core) and are therefore quite harmless compared with wider, full penetration cracks.

(iii) The equilibrium requirement for partial penetration cracks can be satisfied by equating the tension force in the skin to the compression force in the core such that no assistance needs to be provided by the steel. There is no danger at all that only one very wide crack will occur. Equation (14) should therefore have been $r_{\text {orit. }}=0$.

214. Equation (6a) is indeed ' . . . merely a statement of equilibrium . . . but it is erroneous to state that 'As such it is extremely pessimistic'. The arguments which are directed towards equation (6a), for example, the length over which bond slip occurs, are the factors which have been considered in deriving equation (8). Equation (6a) states that the force in the steel should be capable of cracking the concrete rather than yielding indefinitely. The facts that the force is due to the strain in the concrete (and must therefore be of limited magnitude and sometimes inadequate to cause yield in the steel) and that the force must be transferred over a finite length of bar, are irrelevant to equation (6a). This equation is therefore correct as it is unless some allowance is considered justified for restraints which are reasonably well distributed as given in equation (6b). Considerably more data are necessary, however, before reliable values of $r_{m i n}$. could be given for different conditions. In the absence of such data it is necessary to recommend $r_{\text {critt. }}$ for all cases where the bay lengths are very long. A modified $r_{\text {crit. }}$ value is considered in the reply to $\mathrm{Mr}$ Erinoso.

215. Although yielding of the steel provides a limiting condition which must be considered for continuous lengths of wall, the transposition of equation (8) as given by $\mathrm{Mr}$ Irving is both valid and useful for predetermined lengths of wall. This has already been considered in the reply to Mr Hilton.

216. Mr Irving has made useful calculations concerning creep effects to confirm that the initial compressive creep exceeds the subsequent tensile creep when the usual temperature rises due to the heat of hydration are considered. If a low temperature rise is considered it is shown that the subsequent tensile creep can more than offset the initial compressive creep. The statements that tensile stresses on cooling can be reduced by reducing both 'the heat of hydration' and 'the rate of cooling subsequent to casting' are correct except that the word 'casting' should be replaced by 'the attainment of the maximum temperature due to heat of hydration'.' The rate of cooling, subsequent to casting and while the temperature is rising, should be increased as rapidly and as quickly as possible consistent with the avoidance of thermal shock (i.e. a sudden sharp increase in rate of cooling).

217. The subsequent comments indicate that two vital facts have been overlooked. The rate of heat evolution at low temperatures is greatly reduced. This can greatly reduce the maximum temperature rise and partly explains why that given by the test 
blocks was so low. Casting in warm summer weather must necessarily accelerate the rate of heat evolution and hence increase the initial temperature rise.

218. Two of the three cracks referred to in Fig. 7 did not appear until some weeks after casting. This emphasizes the limited ability of tensile creep to relieve contraction strains. A long seasonal cooling period does not necessarily increase the tensile creep strain since specific creep reduces rapidly with time as shown by Fig. 12 . High early tensile stresses just below the tensile strength can give much higher total creep strains than tensile stresses which build up gradually with time.

219. Bays which are cast overlapping the previous lift like brickwork would not produce an effective reduction in crack width at construction joints for two reasons. First, tensile strength of the immature bay is small compared with the mature bay underneath. Second, the contraction of the concrete across the width of the crack is given by the crack width $\times$ contraction strain which is negligible. The upper bay could only prestress the bays underneath if considerable creep occurred for considerable distances on both sides of the crack. This is not feasible.

220. Mr Barrett gives an interesting account of the construction of a tank wall which confirms that thermal effects are extremely important and that delayed stripping of formwork can aggravate the difficulties. The shutters were presumably made of timber. Some explanation is necessary, however, for Mr Barrett's remarkable statement that 'Ambient temperatures varied from $32^{\circ} \mathrm{F}$ in January to $75^{\circ} \mathrm{F}$ in July ... cumulatively they had no appreciable effect either on the rate of rise or the period to reach maximum temperature.' Mr Aitken also claimed that the temperature rise was the same in summer and winter although he did at least concede that there was a delay of $20 \mathrm{~h}$ in the winter hydration temperature peak.

221. It is well known that the temperature at which hydration takes place greatly affects the rate of heat development. For example, the values according to Lerch and Ford ${ }^{16}$ for the heat of hydration developed after $72 \mathrm{~h}$ at different temperatures are given in Table 1 . One possible explanation is that rapid hardening Portland cement was used in cold weather and ordinary Portland cement was used in summer. This would give heats of hydration after $72 \mathrm{~h}$ of the order of 52.9 and $68.0 \mathrm{cal} / \mathrm{g}$ of cement. Even if this were the case, however, Mr Barrett's readings must surely have indicated a seasonal variation.

Table 1. Heat of hydration (cal/g) developed after $72 \mathrm{~h}$ at different temperatures for cement types I and $1 \mathrm{II}^{16}$

\begin{tabular}{l|c|c|c}
\hline Temperature & $40^{\circ} \mathrm{F}$ & $75^{\circ} \mathrm{F}$ & $90^{\circ} \mathrm{F}$ \\
\hline Type I (OPC) & 36.9 & 68.0 & 73.9 \\
Type III (RHPC) & 52.9 & 83.2 & 85.3 \\
Type IV (low-heat) & 25.7 & 46.6 & 45.8 \\
\hline
\end{tabular}

222. The use of 'ductubes' is a very satisfactory method of forming predetermined contraction joints. At Berkeley Nuclear Power Station, Glos., they were filled with an expanding grout, again with complete success.

223. The chemistry of the cement as it affects hydration is well known. Table 1 clearly shows that the use of low-heat Portland cement is one way of reducing thermal cracking. However, elementary precautions to reduce the as-placed concrete temperature as we suggested is another which can be used instead, or in addition.

224. Mr Beeby and Mr Weaver have provided details of an interesting test which shows that thermal effects can be almost the exclusive cause of movements in concrete 
at early ages. Unfortunately, however, the test was not typical in that the concrete when placed was already hot. Its initial temperature is given as $50^{\circ} \mathrm{C}$ and must therefore have been about $40^{\circ} \mathrm{C}$ above the initial temperature of the reinforcement which was equal to ambient. It is hardly surprising that the subsequent expansion of the bars would cause them to buckle and to reduce the bond greatly. It is incorrect to assume, however, that the bond strength was affected at the ends only: it would have been affected throughout the length of the bar. The maximum slope as given in Fig. 19, for example, depends on the bond strength and is clearly too steep.

225. If it is assumed that the bond strength was reduced in this instance to about a quarter of its usual value then equation (8) predicts that the crack spacing is given by

$$
220 \text { in. } \geqslant s \geqslant 110 \text { in. }
$$

That is, cracks would occur at between $18 \mathrm{ft}$ and $9 \mathrm{ft}$ approximately. Since the test panel was only $11 \mathrm{ft}$ long no intermediate cracking would be expected since equation (8) predicts, in fact, that bond failure would occur in these circumstances.

226. The steel yields when both the bay length exceeds the crack spacing as given by equation (8) and $r$ is less than $r_{\text {crit. }}$. Once this is appreciated it is clear that the statement that '...tensile stresses in the steel at the ends... cannot become large ... ' is in error. Some bond strength would have existed throughout the length of the bars but, because of the test conditions, was relatively small.

227. A large reduction in bond strength does not usually occur since the difference in temperature of the steel and the concrete initially is far less than $40^{\circ} \mathrm{C}$. Even the subsequent rise in temperature due to hydration is considerably less than this value. In this case, since the concrete and steel are experiencing similar changes in temperature and because the concrete has developed some mechanical strength at this stage, buckling of the steel can be prevented.

228. Mr Beeby and Mr Weaver have given some very useful data concerning the use of plywood and steel shutters. The advantages of good quality control and mix design are again demonstrated by their comparison between concretes with two different cement contents. The importance of the type of aggregate and the dangers of thermal shock are also emphasized. Thermal shock has already been considered in the replies to $\mathrm{Mr}$ Aitken and Mr Handcock.

229. Mr Kaill comments on the stripping of shutters and the possibilities of thermal shock. These have been discussed in the reply to $\mathrm{Mr}$ Dewar.

230. Mr Erinoso makes several interesting comments and gives further useful data in Fig. 22. The low shrinkage for the concrete in the test blocks has been considered in the reply to Mr Dewar. Construction/contraction joints have been discussed in the reply to Mr Hilton.

231. The statement that 'This demonstrates the ineffectiveness of mild steel reinforcement, when used to accommodate thermal stresses in gravel concrete' simply because steel and gravel concrete have the same thermal coefficient of expansion, is very surprising since this consideration is largely irrelevant for restrained members. The primary function of the steel is to provide some tensile strength in the wall even if the concrete cracks. For unrestrained members it is an advantage to have similar coefficients of expansion.

232. In reply to $\S 177$ the provision of $r_{\text {erit. }}$ ensures controlled cracking either for a continuous length of wall (where intermediate cracks can always occur) or for short bay lengths (which may be shorter than the crack spacing predicted by equation (8)). The stress induced in the concrete, $f_{\mathrm{ct}}$, is indeed a function of the distance from the nearest crack, if this distance is less than the crack spacing given by equation (8). The location of cracks is given first by construction joints and then, if the bay lengths are long enough, by equation (8).

233. Mr Erinoso comments that it is surprising that 'after three days, foundation restraint appears to have an insignificant effect on the strains at the top and bottom of the lift'. Reference to the ambient and block temperatures in Fig. 9, however, 


\section{DISCUSSION}

shows that these coincide after three days. Since thermal effects are the major causes of movement, similarities in wall and base temperatures tend to produce similarities in overall strain. The strains for lines B and D were intermediate between those for lines $A$ and $D$, and the strains for line $E$ were less than those for line $D$, as expected from their relative heights from the base of the lift. The crack between points 2 and 3 has been discussed in the reply to Mr Smyth-Osbourne.

234. A number of contributors have implied that $r_{\text {crit. }}$ appears rather high. The 'typical' cracking referred to by $\mathrm{Mr}$ Smyth-Osbourne was severe cracking which occurs within a few days of casting. It is also noted above that there are similarities in movements of wall and base after a few days. A modified value of $\boldsymbol{r}_{\text {orit. }}$ using the 7 day rather than the 28 day tensile strength, $u_{\mathrm{t}}$, would give a lower value of $r$ which would give controlled cracking for the most important, the initial, period.

\section{References}

5. British Standardos Institution. Design and construction of reinforced and prestressed concrete structures for the storage of water and other aqueous liquids. CP 2007 (1960), London.

6. Hannant D. J. Strain behaviour of concrete up to $95^{\circ} \mathrm{C}$ under compressive stress. Paper 17. Conference on Prestressed concrete pressure vessels. 1966.

7. Browne R. D. Properties of concrete in reactor vessels. Paper 13. Conference on Prestressed concrete pressure vessels. 1966.

8. Lewis D. J. et al. Long-term thermal creep effects in pressure vessels. Paper 32. Conference on Prestressed concrete pressure vessels. 1966.

9. Bonnell D. G. R. and Harper F. C. The thermal expansion of concrete. Proc. Instn civ. Engrs, 1950, 33 (Feb.) 320-330.

10. Blanks R. F. Comparison of selected Portland cements in mass concrete tests. Proc. Am. Concr. Inst., 1934, 30 (Sept./Oct. 1933) 9-20.

11. Verbeck G. J. and Foster C. W. Long-time study of cement in concrete. Chapter 6. The heats of hydration of the cements. Proc. Am. Soc. for Test Mater., 1950, 50, 1235-1262.

12. Carlson R. W. A simple method for the computation of temperatures in concrete structures. J. Am. Concr. Inst., 1937, 34 (Nov./Dec.) 89-102.

13. Ross A. D. and BraY J. W. The prediction of temperature in mass concrete by numerical computation. Mag. Concr. Res., 1949 (Jan.) No. 1, 9-20.

14. Construction Industry Research and Information Association. Bulletin No. 4 (July) 1967. (Research Project No. 66.)

15. Hughes B. P. Rational design of high quality concrete mixes using modern concepts. Concrete Journal, 1968, 2 (May) No. 5, 212-222.

16. LERCH W. and FORD C. L. Long-time study of cement performance in concrete, Chapter 3: Chemical and physical tests of the cements. J. Amer. Concr. Inst, 1948, 44 (April) 743-795. 